\title{
Results of a Sub-Scale Model Rotor Icing Test
}

Robert J. Flemming

Sikorsky Aircraft Division

United Technologies Corporation

Stratford, Connecticut

Thomas H. Bond

National Aeronautics and Space Administration

Lewis Research Center

Cleveland, Ohio

and

Randall K. Britton

Sverdrup Technology, Inc.

Lewis Research Center Group

Brook Park, Ohio

Prepared for the

29th Aerospace Sciences Meeting sponsored by the American Institute of Aeronautics and Astronautics Reno, Nevada, January 7-10, 1991 


\title{
RESULTS OF A SUB-SCALE MODEL ROTOR ICING TEST
}

\author{
Robert J. Flemming \\ Senior Design Engineer \\ Sikorsky Aircraft Division, UTC \\ Stratford, Connecticut \\ Thomas H. Bond \\ Aerospace Engineer \\ NASA Lewis Research Center \\ Cleveland, Ohio \\ Randall K. Britton \\ Icing Research Engineer \\ Sverdrup Technology, Inc. \\ NASA Lewis Research Center Group \\ Cleveland, Ohio
}

\begin{abstract}
A heavily instrumented sub-scale model of a helicopter main rotor was tested in the NASA Lewis Research Center Icing Research Tunnel (IRT) in September and November 1989. The four-bladed main rotor had a diameter of $1.83 \mathrm{~m}(6.00 \mathrm{ft})$ and the $0.124 \mathrm{~m}$ (4.9 in) chord rotor blades were specially fabricated for this experiment. The instrumented rotor was mounted on a Sikorsky Aircraft Powered Force Model, which enclosed a rotor balance and other measurement systems. The model rotor was exposed to a range of icing conditions that included variations in temperature, liquid water content, and median droplet diameter, and was operated over ranges of advance ratio, shaft angle, tip Mach number (rotor speed) and weight coefficient to determine the effect of these parameters on ice accretion. In addition to strain gage and balance data, the test was documented with still, video, and high speed photography, ice profile tracings, and ice molds. This paper presents the sensitivity of the model rotor to the test parameters, and compares the results to theoretical predictions. Test data quality was excellent, and ice accretion prediction methods and rotor performance prediction methods (using published icing lift and drag relationships) reproduced the performance trends observed in the test. Adjustments to the correlation coefficients to improve the level of correlation are suggested in this paper.
\end{abstract}

\section{NOTATION}

$\begin{array}{ll}\mathrm{C}_{\mathrm{L}} / \sigma & \text { Lift Coefficient/Solidity } \\ \mathrm{C}_{\mathrm{Q}} / \sigma & \text { Torque Coefficient/Solidity } \\ \text { LWC } & \text { Liquid Water Content, } \mathrm{g} / \mathrm{m}^{3} \\ \mathrm{MVD} & \text { Droplet Diameter, } \mu \mathrm{m} \\ \mathrm{T} & \text { Static Air Temperature, }{ }^{\circ} \mathrm{C} \\ \overline{\mathrm{X}} & \text { Propulsive Force } \\ \sigma & \text { Solidity }(0.173) \\ \mu & \text { Advance Ratio } \\ \Omega \mathrm{R} & \text { Rotor Tip Speed } \\ \Delta & \text { Difference }\end{array}$

\section{INTRODUCTION}

The majority of military and civil helicopters have restricted or no clearance for operating in forecasted 
icing conditions. This is due in part to the lack of adequate rotor deicing systems, extreme rotor sensitivity to ice accretion, and the expense of system qualification for the full icing envelope. Procedures have been established to use icing tankers and/or ground icing facilities for full-scale icing flight testing, but these approaches have not adequately simulated natural icing conditions. Because of the trend toward design of all-weather rotorcraft, it is necessary to develop and validate experimental techniques to understand the effects of ice on rotor performance and to determine the design requirements for rotor ice protection. Analytical methods are now being developed to predict rotor performance in icing, including ice accretion and ice shedding. The use of a model rotor to provide a less expensive and more repeatable source of test data will aid in the validation of these analytical methods and support the overall goal toward more expedient certification procedures (Figure 1). The French undertook a model icing program where a 1/4-scale model rotor was tested in the ONERA S1MA wind tunnel at Modane, France. ${ }^{1}$ This testing showed that a model program had promise, but the data acquired were too limited to provide a correlation base. However, this testing prompted the interest of rotorcraft icing researchers in the United States. A rotor icing consortium evolved to identify and pursue an approach to model rotor testing in an icing environment. NASA Lewis Research Center undertook a program with university and industry participants to demonstrate the usefulness of the model rotor test technique as an approach for obtaining meaningful icing data for rotating systems.

\section{TECHNICAL APPROACH}

The Rotor Icing Consortium is composed of members from the four major helicopter companies: Bell Helicopter Textron, Boeing Helicopters, McDonnell Douglas Helicopters, and Sikorsky Aircraft Division of United Technologies, plus representatives from NASA Lewis Research Center (LeRC), U.S. Army Aviation Research and Technology Activity-AVSCOM, and Texas A\&M University. The consortium worked during the early part of the program to identify the necessary tasks and the means to achieve them. Each of the members was given specific responsibilities, as outlined in Table 1.

TABLE I. Rotor Icing Consortium Responsibilities For Model Rotor Icing Test.

\begin{tabular}{||l|l||}
\hline \multicolumn{1}{|c|}{ Company } & \multicolumn{1}{c|}{ Tasks } \\
\hline \hline NASA Lewis Research Center & $\begin{array}{l}\text { Project coordination; Icing test technique } \\
\text { development for model rotor icing test }\end{array}$ \\
\hline Propulsion Directorate - AVSCOM & Icing tunnel test hardware \\
\hline Bell Helicopter & PC-based safety of flight system \\
\hline Boeing Helicopters & Test plan; Analytical modeling \\
\hline McDonnell Douglas Helicopters & $\begin{array}{l}\text { Composite rotor blade design and construction; Test } \\
\text { support }\end{array}$ \\
\hline Sikorsky Aircraft & $\begin{array}{l}\text { Powered force model and associated hardware; Data } \\
\text { acquisition and reduction; Test support }\end{array}$ \\
\hline Texas A\&M University & $\begin{array}{l}\text { PC-based data acquisition and reduction system; } \\
\text { Test support }\end{array}$ \\
\hline
\end{tabular}

A two model approach was selected as the most effective means to accomplish the program goals. A lightly instrumented OH-58 tail rotor (Figure 2) that had been modified to approximately operate as a main rotor was chosen as the initial test article. This would be followed by the more sophisticated Sikorsky Basic Model Test Rig (BMTR) Powered Force Model (PFM) (Figure 3) to provide detailed rotor performance measurements. The OH-58 Icing Research Tunnel (IRT) entry would establish operational techniques for the more complex model, 
define tunnel test capabilities for a rotorcraft entry, and gather preliminary data. The OH- 58 model test was completed in October 1988 and the results presented at the 1989 American Helicopter Society Annual Forum. ${ }^{2}$ The conclusion of this initial test indicated the tunnel was capable of being used for model rotor icing. The test techniques developed for the OH-58 entry were refined to provide a greater probability of success for the PFM entry.

The initial PFM IRT entry was scheduled for an 8 week period during July to September, 1989. During this time the model was installed and icing testing began. However, blade tracking problems, high humidity, and warm ambient conditions precluded testing over the desired range of tunnel speeds, rotor lifts, and tunnel temperatures. A total of 44 icing encounters occurred in the 14 days of testing.

At the end of this initial test period, the model was removed and a second entry scheduled for November 1989. Between tests, the model was serviced, data reviewed, high speed motion picture capability added, and methods for improving blade track were prepared. This second entry resulted in 41 icing encounters in 8 test days, and expanded the temperature envelope and included variations in liquid water content and droplet diameter. Reference 3 presents a portion of the test data from these tunnel entries. This paper and Reference 4 provide a review of the testing and present additional data and comparisons with theory.

\section{MODEL AND FACILITY DESCRIPTIONS}

\section{Icing Research Tunnel}

The IRT (Figure 4) is a closed-loop refrigerated wind tunnel. A $5000 \mathrm{hp}$ fan provides airspeeds up to 134 $\mathrm{m} / \mathrm{s}(300 \mathrm{mph})$. The 21,000 ton capacity refrigeration heat exchanger can vary the total temperature from -1.1 to $-42{ }^{\circ} \mathrm{C}$. The spray nozzles provide droplet sizes from approximately 10 to $40 \mu \mathrm{m}$ median volume diameter (MVD) with liquid water content (LWC) ranging from 0.2 to $3.0 \mathrm{~g} / \mathrm{m}^{3}$. The tunnel is $1.8 \mathrm{~m}(6 \mathrm{ft})$ high and $2.7 \mathrm{~m} \mathrm{(9ft)}$ wide.

Armor plates were attached to the walls of the tunnel test section during the model rotor test to protect personnel in the control room. Video systems were installed to monitor the test area and local blade positions, and to provide tracking information. For several runs $0.635 \mathrm{~mm}(0.025 \mathrm{in}$.) aluminum sheets were placed on energy absorbing material and attached to the armor plating in line with the rotor disk plane. The shed ice made permanent dents in the sheets that will be calibrated to calculate the impact energy of the ice that struck them. A high speed $16 \mathrm{~mm}$ camera was used to capture ice shedding from the blades. The movies were taken at 2000 frames per second and capture approximately a $60^{\circ}$ arc of the rotor rotational field.

\section{Powered Force Model}

The Sikorsky PFM is a self-contained, general purpose rotor test rig. The load measuring systems, rotor power, and control mechanisms are located within the model frame. The PFM can accept a wide range of rotor systems and fuselage skins. The rig is capable of accepting a fuselage and powered tail rotor, each containing its own balance system. For this project only the main rotor and its balance were installed. The attachment of power, lubrication, control and signal lines complete the model installation. The main rotor was located $1.02 \mathrm{~m} \mathrm{(3.35 \textrm {ft } )}$ above the tunnel floor, about $0.10 \mathrm{~m}(0.33 \mathrm{ft})$ above the centerline. The US Army UH-60A model skins were used to enclose the balance and rotor hardware (Figure 3). A small rotor head faring contained the hub accelerometers. While the fuselage skins are scaled for a $2.86 \mathrm{~m}(9.37 \mathrm{ft})$ rotor, tunnel dimensions dictated the use of a $1.83 \mathrm{~m}$ $(6.00 \mathrm{ft})$ rotor for this test.

The rotor head used for this project (Figure 5) was a Sikorsky-designed and NASA Langley-owned general purpose, four bladed, fully articulated head with coincident flap and lag hinges at the 8.3 percent $(76 \mathrm{~mm}$ or 3.00 in) radial station. The hub has adjustable lead-lag dampers and for this test it had a zero pitch-flap coupling $\left(\delta_{3}\right)$. In order to preserve a consistent lead-lag damping coefficient during the variation in the IRT temperature, the rotor viscous dampers were electrically heated to maintain the fluid at about $10^{\circ} \mathrm{C}$. Potentiometers mounted on the flap, lead-lag, and pitch axes provide positional information for the rotor system relative to the shaft.

The PFM main rotor was driven by two Task 3-phase variable frequency induction electric motors. As installed, the motors can rotate at speeds up to $8000 \mathrm{rpm}$. A 3.5 to 1 reduction gear box operates the rotor shaft speed to a maximum of $2286 \mathrm{rpm}$, which equates to a rotor tip speed of $219 \mathrm{mps}$ ( $718 \mathrm{fps})$. Each motor has a 
continuous rating of $60 \mathrm{hp}$. Rotor speed was measured using an optical encoder. Model power was supplied by a variable frequency motor-generator set provided by the Aeroflightdynamics Directorate, US Army Aviation Research and Technology Activity. The motor-generator set featured a digital closed-loop rpm feedback control, which maintained a set rotor speed under the power variations that occurred due to ice accretion, shedding and control changes.

Individual elements of the model are described in the following paragraphs.

Load Measurement System. - The rotor forces and moments (except torque) were measured using a Modern Machine 367-301 strain gage balance. The balance was gimbal-mounted to the model frame with a soft spring attachment, which lessens the possibility of ground resonance. The balance was electrically heated to maintain it at the calibration temperature of $20^{\circ} \mathrm{C}$. Rotor torque was obtained by measuring the reaction force between the gearbox (which was mounted on bearings) and the gearbox frame with a Revere Model USP1-5-B load cell. A 102 channel slipring was used to transfer the rotating system signals from blade gages, pushrods, motion hardware, and accelerometers to the fixed system. It also provided power to the damper heaters.

Control System. - The swashplate control components consisted of rotating pushrods and scissors, the swashplate, three electromechanical actuators, and a stationary scissors. Control inputs were made at the control console with cyclic and collective joystick controllers. The input signals were electronically mixed by the controller which then moved the model actuators. A closed-loop feedback circuit monitored the actuator motion. Resolved shaft axis cyclic and flapping first harmonic coefficients were obtained from potentiometers located on the rotorhead. These values were displayed graphically and numerically to facilitate rotor trimming.

Shaft Angle Control. - Shaft angle for this test was set by the model operator using a remotely driven linear actuator located on the test rig support frame. A pitch arm transferred the linear motion of the actuator to the rotating motion of the model shaft. This resulted in both a translational and model pitch motion for the rotor. The model support shaft angle range was from -10 to $+3^{\circ}$. The angles set by the shaft angle control must be corrected by the gimbal deflection angle and aerodynamic wall corrections to obtain the true total shaft angle.

\section{Main Rotor Blades}

Ten blades were designed and built by the McDonnell Douglas Helicopter Company using molds built by Sikorsky Aircraft. The blades for the $1.83 \mathrm{~m}(6.00 \mathrm{ft})$ diameter rotor had NACA 0012 airfoils with a chord of $0.124 \mathrm{~m}(4.88 \mathrm{in})$, a $-10^{\circ}$ linear twist, and a taper ratio of 1 . The blade weight had to be kept to a minimum to stay within rotor head stress limits at the design rotor speed. The weight constraint resulted in a thin walled hollow spar, an unsupported trailing edge, and an unpainted airfoil surface. These design restrictions led to problems during cold temperature operations. The blades behaved differently from each other, causing variations in tracking. It is believed that temperature cycling and the unfilled trailing edge area caused the tracking changes. Two of the blades were instrumented with strain gages in the flatwise, edgewise, and torsional axes to provide blade loading information for safety of flight. The data from the edgewise strain gages proved to be very useful in identifying shedding events. This prompted the addition of root edgewise strain gages to the noninstrumented blades prior to the second entry.

The rotor blades were marked on their upper surfaces with the blade number and spanwise decade percentage marks to provide identification of the blade being monitored and the relative location of the ice that was shed (see Figure 3).

\section{INSTRUMENTATION AND DATA SYSTEM}

\section{$\underline{\text { Test Parameters }}$}

The test parameters measured fell into two main categories - those that were of research interest and those that were required solely for safety-of-flight. The 41 parameters in the first category were processed by the Dynamic Data Acquisition System (DDAS) and saved on both digital tape and floppy disks. Derived parameters were also computed using the DDAS and saved for further analysis. The test parameters used for analysis include the following:

Main rotor balance loads (6 components) 
Main rotor torque and speed

Tunnel temperature, and static and total pressure

Liquid water content (measured by Johnson-Williams probe)

Control positions (4) and instrumented blade angles (3)

Resolved blade flapping and coning (3)

Instrumented blade flatwise (3), edgewise (4), and torsional (2) loads

Blade root edgewise load for each blade (November entry)

Gimbal and rotor head accelerations (4)

Pushrod loads (2)

Derived parameters calculated from the above test parameters will be discussed later in the paper.

Each of the parameters in the list above (except the Johnson-Williams LWC and the root edgewise loads)

were stored on an analog tape along with a voice track, a 1-per-revolution signal, and a time code. These parameters used 40 of the available 42 tape tracks.

Several derived parameters from the transducer outputs were computed and displayed at a rate of once per second to allow the model operator and Safety Of Flight (SOF) engineer to monitor loads and set target test conditions. These values accounted for tunnel blockage and buoyancy corrections, coordinate transformations, transfers, and balance interactions.

The SOF system recorded an additional 47 parameters, saved temporarily in the event of a model malfunction, but not archived for further analysis. Included on the tape were oil pressure, oil and water flow rates, drive system and motor temperatures, motor accelerations, heater voltages, limit switch and solenoid positions, rotor speed, and reference voltages.

\section{Dynamic Data Acquisition System (DDAS)}

The DDAS, safety of flight system, and model operations consoles were all located in the control room of the IRT. Data parameters were recorded on both analog and digital systems. The analog system was installed primarily as a safety of flight system and has not yet been used for data analysis. The heart of the digital system was a Digital Equipment Corporation PDP11/34 minicomputer. This test used 41 of the available 128 data channels, which were conditioned, digitized, and transferred to the PDP11 by a Neff System 620 . Simultaneous sample and hold amplifiers froze the analog channels before digitizing to maintain time correlation of each parameter in each time frame(ie., in each data snapshot). The system is configured to acquire data in both time and rotor domain. Data were acquired at a rate of 16 samples per rotor revolution during the icing test. Data acquisition hardware and software were developed to reduce the quantity of stored data, ie., a continuous record of a 150 second icing run with a rotor tip speed of $213.4 \mathrm{mps}(700 \mathrm{fps}$ or $37.1 \mathrm{~Hz})$ would produce 3.7 million records, more than the DDAS can handle. Therefore, data were digitized only for the first 10 revolutions of each second (160 samples per data burst). The data was transferred from the DDAS to a PC/AT computer for further processing.

\section{Safety of Flight System}

Three pieces of equipment make up the model SOF instrumentation. An automated datalogger was used to monitor drive component temperatures, fluid flow and pressures, damper and balance temperatures, and various status voltages. Critical SOF parameters such as balance loads, pushrod loads, blade loads and fixed system vibrations were manually monitored during testing. Each data parameter was sent to a 42 track FM tape system which served as both an incident recorder and an analog data archive system.

\section{Data Processing Equations}

A number of commonly used rotorcraft parameters can be computed from the measured test data. An integral part of the processing of this information is the correction of the wind tunnel data for the effects of the tunnel walls. These corrections increase the effective tunnel speed and alter the rotor wake flow angles. Non-dimensional terms can also be calculated to normalize the data for day-to-day changes in ambient pressure, rotor speed fluctuations, and temperature variations. Data corrections must also be made for shaft torque tares, gravity tares, the induced angle of attack, and three dimensional buoyancy and solid blockage effects. The coordinate systems, data correction equations, and a description of the derived parameters will be included in a 
future NASA Contractor Report.

\section{TEST PROCEDURE}

\section{Test Techniques}

The test techniques used in the IRT were based on previous model operating experience and procedures developed during the July to October 1988 OH-58 tail rotor entry in the tunnel (Reference 2). Each icing run was recorded on the DDAS and video systems. The video provided a viewing history of the ice accretion and shedding. There were three separate video systems: one for safety monitoring, one for blade tracking (which also provided good ice profile shapes near the blade tip), and one that allowed close-up images of the rotor blades. The three systems were strobe driven by a signal off the rotor shaft angle encoder. This gave a "frozen" image of the blade. The close-up data video system was installed on a tilt and pan mechanism along with a $35 \mathrm{~mm}$ camera that had a $400 \mathrm{~mm}$ zoom lens. The data video system had the capability of traversing the entire diameter of the main rotor while allowing zoom shots of as small a span as $0.10 \mathrm{~m}$ (3.94 in) of the blade leading edge. The $35 \mathrm{~mm}$ camera was focused on the same close-up viewing area as the video camera, allowing pictures with greater resolution and clarity to be taken. Both the data video and the $35 \mathrm{~mm}$ camera were triggered from the same strobe to provide an accurate replication of the video image for the $35 \mathrm{~mm}$ camera.

During the test run, information was collected on the DDAS and the video systems, and the tunnel conditions were monitored. Liquid water content information (rise time, cloud stabilization, and spray bar lag from spray initiation) was recorded from the Control Room console output and a Johnson-Williams (J-W) LWC meter. Tables providing the main rotor operating conditions were printed out at the beginning and end of each run. Spray times, temperatures, and general comments were noted.

Post-run information was gathered by taking $35 \mathrm{~mm}$ camera photographs, recording ice tracings, noting visual observations, and making ice molds. Pictures were taken of the blade planform, an end profile, and any unusual ice formations. Close-up shots of ice growths were taken to record their minute detail. A heated aluminum block with a cut-out contour of the airfoil shape was used to make a clean slice through the ice formation. A template was then held against the ice shape and a tracing made. Measurements of the ice thickness along the profile were taken at various chord locations. Visual observations were recorded about the kind of ice, any secondary growth, and frost formation. Molds were taken of two blades on three separate occasions.

\section{$\underline{\text { Test Operation }}$}

A typical test run consisted of bringing the PFM up to speed to exercise the rotor, then shutting the model down to take static balance and gage readings. The model was then brought up to operating speed and once the rotor was stabilized, a dynamic zero (wind off, zero collective) was taken. After this record the rotor rpm was dropped to some nominal level while the tunnel controls were set and the tunnel started up. When the tunnel conditions were stable the model operator returned to the desired speed, set the test point conditions, and took an uniced baseline point. The data engineer then initiated data acquisition and the tunnel operator initiated the spray sequence. At the end of the run the tunnel rpm was brought down to idle (taking approximately 2 minutes) while the model operator lowered the rotor speed to reduce centrifugal loads on the accreted ice. When the tunnel test section speed was below $10 \mathrm{kt}$ the rotor was stopped. After the run the researchers entered the test section and documented the results. The assembly was deiced and conditions set for the next run.

\section{TEST DATA}

\section{$\underline{\text { Test Conditions }}$}

A total of 108 test runs were completed. Of those, 85 were icing events with the rest comprised of systems check-out, gravity and hub tares, balancing, and baselines. The test matrix was set up to include a range of conditions for a number of rotorcraft performance parameters under varied IRT conditions. For this test the 
temperature range was -1.7 to $-30.5^{\circ} \mathrm{C}$, the LWC range was 0.35 to $1.24 \mathrm{~g} / \mathrm{m}^{3}$, and the MVD range was 13 to 23 $\mu \mathrm{m}$. The predominant condition was at $-15^{\circ} \mathrm{C}, 0.50 \mathrm{~g} / \mathrm{m}^{3} \mathrm{LWC}$, and $15 \mu \mathrm{m}$ MVD. Icing encounter times were from 44 to 158 seconds. Thrust, propulsive force, advance ratio, and model rpm were changed, within the above tunnel conditions, to provide a wide scope of performance mapping.

\section{Accuracy and Repeatability}

The $2 \sigma$ accuracy of the rotor loads was estimated to be:

\begin{tabular}{||l|c|c||}
\hline & $\begin{array}{c}\text { Balance full scale, } \\
\text { percent }\end{array}$ & $\begin{array}{c}\text { Typical measurement, } \\
\text { percent }\end{array}$ \\
\hline Lift & 0.2 & 1.1 \\
Drag & 0.2 & 10.0 \\
Torque & 0.7 & 2.5 \\
\hline
\end{tabular}

The rotor head motion hardware consisted of blade pitch, flap, and lead-lag potentiometers. These potentiometers were of the single turn conductive plastic type. The manufacturers' rated accuracy was $\pm 0.13^{\circ}$. The total system accuracy was measured at $\pm 0.3^{\circ}$.

The ability to repeat a test condition was a major goal of this test program. Rotorcraft icing flight test data has been subject to considerable data scatter, making the application of that data to code validation and basic research difficult. A portion of the observed scatter occurs due to variations in the accretion of ice on an airfoil ${ }^{5}$, but most of the scatter comes from uncontrolled variation in the cloud. The trends from the IRT data show some scatter, but the data appear to be of much better quality than previous data available in the public domain. Figure 6 shows excellent repeatability for a condition that was replicated five times. Other replicated conditions show very good repeatability. Figure 7 shows ice shape comparisons for two different repeat conditions and illustrates the small amount of variance between typical runs.

\section{$\underline{\text { SCALING }}$}

In a test of this nature the concept of scaling must be addressed. Ideally, a complete scaling law must include:

1. Similarity of airflow over dry and iced surfaces

2. Similarity of blade reaction to aerodynamic forces

3. Similarity of droplet momentum

4. Similarity of frozen droplet mass flux

5. Similarity of energy balance where freezing occurs

6. Similarity of forces which cause shedding

It should be noted that this test did not deal with scaling in a truly rigorous way. The rotor chord was $0.124 \mathrm{~m} \mathrm{(4.88} \mathrm{in.)} \mathrm{and} \mathrm{tunnel} \mathrm{geometry} \mathrm{constrained} \mathrm{the} \mathrm{model} \mathrm{to} \mathrm{a} 1.83 \mathrm{~m}(6.00 \mathrm{ft})$ diameter rotor which results in a high (0.173) solidity. The rotor chord was kept as large as possible in order to reduce Reynolds number effects. A full scale version of this rotor does not exist. To minimize scale effects, the model was operated at fullscale tip speeds and full-scale tunnel speeds. Tunnel temperatures and pressures represent full scale conditions. These give a model Reynolds number that is lower than the full-scale value by a factor of the full to model scale chord ratio. While scaling of liquid water content, droplet diameter, and icing time are important, the MVD and LWC were not scaled exactly for this test because of spray cloud limitations. Scale relationships have been presented to account for these effects (see Reference 3, for example). Figure 8 shows lines of similitude for various icing conditions. All test conditions which fall on the curve should be similar to each other in terms of icing. For example, it can be seen from the plots that testing a $0.2 \mathrm{~m}$ chord airfoil with an MVD of $20 \mu \mathrm{m}$, an LWC of 0.68 
$\mathrm{g} / \mathrm{m}^{3}$, and an icing time of 180 seconds would be similar to testing a $0.6 \mathrm{~m}$ chord airfoil with an MVD of $40 \mu \mathrm{m}$, an LWC of $0.55 \mathrm{~g} / \mathrm{m}^{3}$, and an icing time of 650 seconds.

\section{DATA ANALYSIS AND CORRELATION}

\section{Baseline Data}

The analysis presented in this paper concentrates on the effect of icing time on performance parameters, primarily rotor lift and rotor torque. The hovering performance of the rotor was determined during tests in the Sikorsky model rotor test facility. The measured hover performance is compared with the model rotor predictions of the CAMRAD/JA code ${ }^{6}$ in Figure 9. These data show that the rotor performance matched theory, using a $\Delta \mathrm{C}_{\mathrm{d}}$ derived from IRT testing (see below).

The forward flight performance of the rotor was determined during dry air tests in the IRT. As expected, rotor torque was higher than that calculated with the Sikorsky Generalized Rotor Performance (GRP) code, using full-scale ( $\mathrm{c}=0.41 \mathrm{~m}$ or $16 \mathrm{in}$.) NACA 0012 airfoil data. Good torque correlation was achieved by adding a $\Delta \mathrm{C}_{d}$ $=0.0026$ to adjust the full-scale airfoil data for the effect of Reynolds number on profile drag (see Figure 10). This profile drag increment is consistent with that derived using Reference 10 methodology.

The IRT causes a significant change in rotor wake geometry. This effect is predictable as described in the Data Processing Equation section of this report. This correction can be substantiated by comparing the test data with the GRP-calculated X-bar, with the calculation performed at the corrected rotor shaft angle. Figure 11 shows good correlation.

The dry air performance of the rotor is given in Figure 12. Typical test conditions are indicated on this figure. The variation of torque for a given lift is due to fluctuations in the shaft angle. As discussed in a later section this variance in shaft angle proves insignificant from an icing analysis viewpoint.

\section{Determining the Onset of Icing}

One step in the analysis of the effect of icing on a rotor is the determination of the time that the spray cloud reached the model, the onset of icing time.

The data were reviewed to determine experimentally the time for this onset of icing. This onset time was based on the Johnson-Williams (J-W) LWC probe (when available) or the beginning of the change in rotor torque and lift. This approach minimized random variations in spray development time and improves the overall data quality for the analysis for parameter comparisons.

\section{$\underline{\text { Liquid Water Content }}$}

The liquid water content and droplet diameter of the spray cloud are dependent on the spray bar water and air pressures, and the tunnel velocity. The pressure values are generated from a set of calibration equations. The above approach gives an accurate setting for LWC, but it does not provide any history of the spray which is necessary to understand the cloud time lag between spray on and model inundation, rise time to the target LWC, and cloud characteristics during the spray. A Johnson-Williams (J-W) liquid water content meter was installed slightly in front of and below the rotor (see Figure 3), providing cloud time history information.

The duration of the spray generally ranged from 44 to 158 seconds. Scale rotor testing must use these shorter times to replicate full scale conditions (see Figure 8). These spray durations include the spray stabilization time. A plot of the J-W LWC data for a number of runs (Figure 13) indicates that there is some rise time prior to reaching the target value (with the rise time increasing at the higher LWC runs), but the spray condition remains relatively close to the desired setting after the ramp up. The cloud reached the model about 10 seconds after the "spray on" command was given. The LWC repeatability is shown for two different spray bar settings in Figure 14.

\section{Ice Shedding}

The ice shedding process is a very important factor in a propeller or rotorcraft icing encounter; this 
phenomena dominates the outcome of the entire icing event. The shedding process is influenced by centrifugal forces, aerodynamic loading, and the elastic deformations of the blades. Shedding can pose several potential problems for rotorcraft. The ice leaving the blades at high tip speeds has substantial energy and can cause fuselage damage for rotorcraft, especially tiltrotor and propeller applications. Also, when ice sheds in a non-uniform fashion an out-of-balance condition can arise resulting in high vibratory loads.

Figure 15 shows a plot of the root strain gage output for each of the blades as a function of time. When a shed occurs there is a large fluctuation in the strain gage reading. There were two major shedding events for this run; one at approximately 25 seconds and another at about 38 seconds. For both events blade number 4 experiences a shed first, followed by sheds from the other blades. Rotor torque, also shown in Figure 15, exhibits a small reduction during minor shedding, with more pronounced changes in torque at major shedding events. There were instances where ice was shed asymmetrically, but the model vibration load limits were not exceeded. Figure 16 shows an example of a section of a blade with ice shed. While this shows a relatively clean break in the ice, the majority of the time there is some residual ice left on the blade after a shed. The condition of the blade surface has an effect on shedding characteristics. While the blades and exposed areas of the hub were wiped clean of any bearing grease prior to every run, post run examination revealed some degree of grease on the inboard portions of the airfoil leading edge. The effects on adhesion properties are not known, but the data examined show that ice shedding was reasonably repeatable.

\section{$\underline{\text { Lift and Torque Increments }}$}

The rotor balance was sized to accommodate the vibratory loads due to ice shedding, and was, therefore too large to measure precisely the low drag (X bar) levels at the primary test speed of $31.1 \mathrm{~m} / \mathrm{sec}(80 \mathrm{kt})$. However, the data show that shaft angle, and hence X-bar, are of secondary importance in the data trends (Figure 17).

The $\Delta$ lift data from the first phase shows a rapid lift loss at the beginning of the ice encounter, indicative of a significant roughness effect on the lift curve shape. Data from the second phase of testing doesn't exhibit the large initial lift loss, more consistent with current theoretical predictions (see Correlation with Theory section of this paper). Other data obtained in this test program show that variation in $\mathrm{C}_{\mathrm{L}} / \sigma$ has no effect on lift loss or torque rise due to icing.

The model was tested over an airspeed (advance ratio) range consistent with the blade envelope. For the advance ratio range tested there is no statistically significant effect on either $\Delta$ lift or $\Delta$ torque.

The data follows expected trends when the LWC is increased. The torque data increases and the lift at constant collective pitch decreases (Figure 18).

The median volume droplet diameter was changed in a range from 13 to $23 \mu \mathrm{m}$ at a constant LWC of 0.75 $\mathrm{g} / \mathrm{m}^{3}$. The results indicate that an increase in MVD size has the expected effect of increasing the torque and decreasing lift (Figure 19).

Temperature was varied from near freezing to very cold $\left(-30.5^{\circ} \mathrm{C}\right)$. Figure 20 shows a plot of the power increase for temperatures ranging from -3.7 to $-15.2^{\circ} \mathrm{C}$. The torque increases as temperature decreases because, in this temperature range, the radial icing extent increases and the outer extent is composed of more glaze ice than rime. As more of the rotor blade is iced the performance penalties become more severe. Figure 21 shows another plot of torque rise for a much colder temperature range, -15.2 to $-30.5^{\circ} \mathrm{C}$. Here, the torque rise trend reverses and actually decreases with temperature. As the temperature decreases the ice shape changes from glaze to rime, and the performance penalties are less. Figures 20 and 21 show plots of the lift loss for these ranges of temperature. The trend is consistent with that of the torque with the exception of the extremely cold temperature $\left(-30.5^{\circ} \mathrm{C}\right)$.

The effects of icing on rotor torque at different tip speeds is shown in Figure 22. For the higher tip speeds a balance between shedding and accretion appears to have been reached such that the torque levels off after roughly 50 seconds of icing time. However, the torque trace for the lowest tip speed indicates a much higher torque towards the end of the data run. This is due to the lower tip speed not inducing shedding.

\section{Correlation With Theory}

Correlation with theoretical methods can involve accretion, shedding, and rotor performance. The correlation presented in this paper uses LEWICE for ice accretion, and computes performance using the Sikorsky Generalized Rotor Performance (GRP) forward flight performance code with the rotorcraft icing subroutine of 


\section{Reference 5 .}

The ability to adequately predict a given ice shape is critical to a rigorous methodology which predicts performance degradation during an icing encounter. The current state of the art in this area is the computer analysis LEWICE', which was developed at NASA LeRC. LEWICE is a two-dimensional code which, given the geometric and atmospheric conditions, will predict the cross-sectional ice shape for a specified icing time. Several comparisons have been made between the predictions of LEWICE and this experimental data. ${ }^{4}$ The local angle of attack was determined with the Boeing Helicopters B65 computer performance code. The Mach number and angle of attack were azimuthally averaged for input into LEWICE as shown to be appropriate by Korkan, Dadone, and Shaw ${ }^{10}$ and Flemming and Lednicer. ${ }^{5}$ The guidelines for time step size and surface roughness were those described by Korkan and Britton. ${ }^{11}$ Figure 23 shows two sample comparisons for a rime condition. The overall agreement is good with slight overprediction by LEWICE on the lower surface. Detailed comparisons have been made for both rime and glaze conditions and the results have been encouraging. ${ }^{4}$

The initial correlation of the PFM performance data included one modification to the Reference 5 equations. The PFM test showed that ice, at least for a small rotor, can extend to (and sometimes slightly beyond) the rotor tip. Capability to vary maximum ice extent was, therefore added to the code.

The correlation of clean rotor performance required an adjustment of the airfoil database for the effect of Reynolds number on profile drag. The Sikorsky NACA 0012 data base was established using test data for a 0.41 $\mathrm{m}$ (16 in.) airfoil model. Based on information contained in Reference 7, an average $\Delta C_{d}$ of 0.0026 has been added to the full-scale 2-D airfoil drag coefficients. This replicates the data well, as shown in Figure 10. The excellence of this correlation also validates the corrections applied to the test data.

The icing correlation can be broken into two time regimes. The first regime exist prior to ice shedding, thereby limiting the analysis solely to a study of ice accretion. The second regime exists after ice shedding begins, adding a somewhat random factor to the correlation.

The correlation centered on incremental rotor lift $\left(\Delta \mathrm{C}_{\mathrm{L}} / \sigma\right)$ and incremental rotor torque $\left(\Delta \mathrm{C}_{\mathrm{Q}} / \sigma\right)$ for input shaft angles and flapping angles. Collective pitch was held constant at the predicted clean rotor trim solution. The variation (build up) in LWC that occurred during the start of the icing encounter (see Figure 13) has been ignored. Emphasis has been placed on the evaluation of trends for tip speed, rotor lift, LWC, droplet diameter, icing time, and temperature. These variations encompass the major terms in the Reference 5 icing relationships.

A key element in the prediction of iced rotor lift and torque changes is the prediction of ice extent. Figure 24 shows a comparison between the observed ice extents from the test and the Reference 5 prediction. Since some shedding of ice may have occurred prior to the post run ice extent observations, it would be expected that the data would fall on or below the Reference 5 line. The points that fall above the line imply that the Reference 5 ice extent boundary temperature should be increased for future correlation work.

Figures 25 and 26 present the predicted temperature trending. The Reference 5 method underpredicts warm icing cases. The observed ice extent from the warm temperature icing ranged in span from 32 to $49 \%$. The predicted ice extent is $48 \%$, excellent agreement considering that some ice may have shed from the blade between the ice accretion and the post tunnel shutdown observations. Ice thickness for these cases were not quantified, but the run $\log$ notes that the ice thicknesses were small. The predicted ice thickness ranges from 0.01 to 0.09 inches, consistent with the "small thickness" observations. The large increments in power at warm icing temperatures have been reported by pilots, but these occurrences are not well documented. Further research in this area is warranted.

Once the blade is fully iced, correlation using Reference 5 relationships is much better. Figures 25 and 26 show that the correlation is very good at $-15^{\circ} \mathrm{C}$ and $-20^{\circ} \mathrm{C}$. However, the prediction is conservative at colder temperatures. An examination of the predicted drag coefficients shows that the Reference 5 code can produce rime drag coefficients that are greater than comparable glaze drag coefficients for small icing times. A reduction in rime drag coefficients can improve correlation significantly. The code has been modified to use glaze ice drag coefficients when those coefficients are less than the predicted rime ice drag coefficients.

\section{CONCLUSIONS}

\section{Concluding Remarks}

The examination of the data from the Powered Force Model (PFM) testing has provided encouraging results. The quality of the test data appears to be excellent. The changes in lift and torque are well documented and 
are remarkably repeatable. The model instrumentation clearly shows the time of shedding events.

The data show the effects of temperature, rotor speed, liquid water content, and droplet diameter on icing. The data trends are generally as expected. Test procedures established for rotorcraft testing in the IRT provided a safe operating environment and produced high quality data for performance analysis. The lift at a constant control collective dropped by up to $15 \%$. Torque increases of $50 \%$ and more were common. The techniques employed have been validated by the results obtained, and the data will be useful for code and scaling research and development.

Comparison of test results were made with the Sikorsky Generalized Rotor Performance (GRP) code predictions. Excellent prediction of moderate temperature $\left(-20^{\circ} \mathrm{C}<\mathrm{T}<-10^{\circ} \mathrm{C}\right)$ performance degradation was achieved. The code slightly overpredicted colder temperature torque rise due to an overprediction of rime ice profile drag. The code underpredicts warmer torque rise, a phenomenon that must be researched further.

\section{$\underline{\text { Future Plans }}$}

The near term goal is the completion of the data analysis for the PFM entries and the continuation of correlation studies. High speed $16 \mathrm{~mm}$ movies will be processed, and this information used with the energy impact data to support ice accretion and shedding model development. Molds taken during the testing will be used to make ice castings for use in simulated ice experiments. The next experimental effort will be a re-entry of the OH- 58 model rotor in the IRT with a calibrated impact energy measurement device. This test will concentrate on documentation of the ice shedding process.

Longer term goals include further model icing tests, coordinated with full-scale rotorcraft icing flight testing. This would follow a logical progression for development and verification of the model rotor test techniques and the analytical methods, and identify where their use in main rotor design is appropriate.

\section{ACKNOWLEDGEMENTS}

It took the efforts of all the consortium members to make this test possible. The authors wish to thank all those involved throughout the development of this project, in particular the IRT Test Installations Division personnel and Sikorsky Aircraft Experimental Aeromechanics Section model operators.

\section{REFERENCES}

${ }^{1}$ Guffond, D.D., "Icing and De-icing Test on a $1 / 4$ Scale Rotor in the ONERA S1MA Wind Tunnel," AIAA Paper 86-0480, Jan. 1986.

${ }^{2}$ Miller, T.L., Bond, T.H., "Icing Research Tunnel Test of a Model Helicopter Rotor," NASA TM-101978, 1989. Also presented at the American Helicopter Society $45^{\text {th }}$ Annual Forum \& Technology Display, May 1989.

${ }^{3}$ Bond, T.H., Flemming, R.J., and Britton, R.K., "Icing Tests of a Sub-Scale Model Main Rotor," Proceedings of the $46^{\text {th }}$ Annual American Helicopter Society Forum, pp. 267-281, May 1990.

${ }^{4}$ Britton, R.K. and Bond, T.H., "A Review of Ice Accretion Data From a Model Rotor Icing Test and Comparison With Theory," AIAA Paper 91-0661, January 1991.

${ }_{5}^{5}$ Flemming, R.J., and Lednicer, D.A., "High Speed Ice Accretion on Rotorcraft Airfoils, " NASA CR-3910, August 1985 .

${ }^{6}$ Johnson, W., "CAMRAD/JA, A Comprehensive Analytical Model of Rotorcraft Aerodynamics and Dynamics," Johnson Aeronautics, 1988.

${ }^{7}$ Keys, C.N., et al, "Estimation of Full-scale Rotor Performance from Model Rotor Test Data, " Journal 
of the American Helicopter Society, vol. 30, no. 4, October 1985.

${ }^{8}$ Britton, R.K., "Elevator Deflection Effects on The Icing Process," AIAA Paper 89-0846, Jan. 1989.

${ }^{9}$ Ruff, G.A., and Berkowitz, B.M., "Users Manual for the NASA Lewis Ice Accretion Prediction Code (LEWICE), " NASA CR 185129, May 1990.

${ }^{10}$ Korkan, K.D., Dadone, L., and Shaw, R.J., "Performance Degradation of Helicopter Rotor Systems in Forward Flight Due to Rime Ice Accretion," AIAA 83-0029, Jan. 1983.

${ }^{11}$ Korkan, K.D., and Britton, R.K., "A Study of Ice Shape Prediction Methodologies," AIAA Paper 90-0753, Jan. 1990.

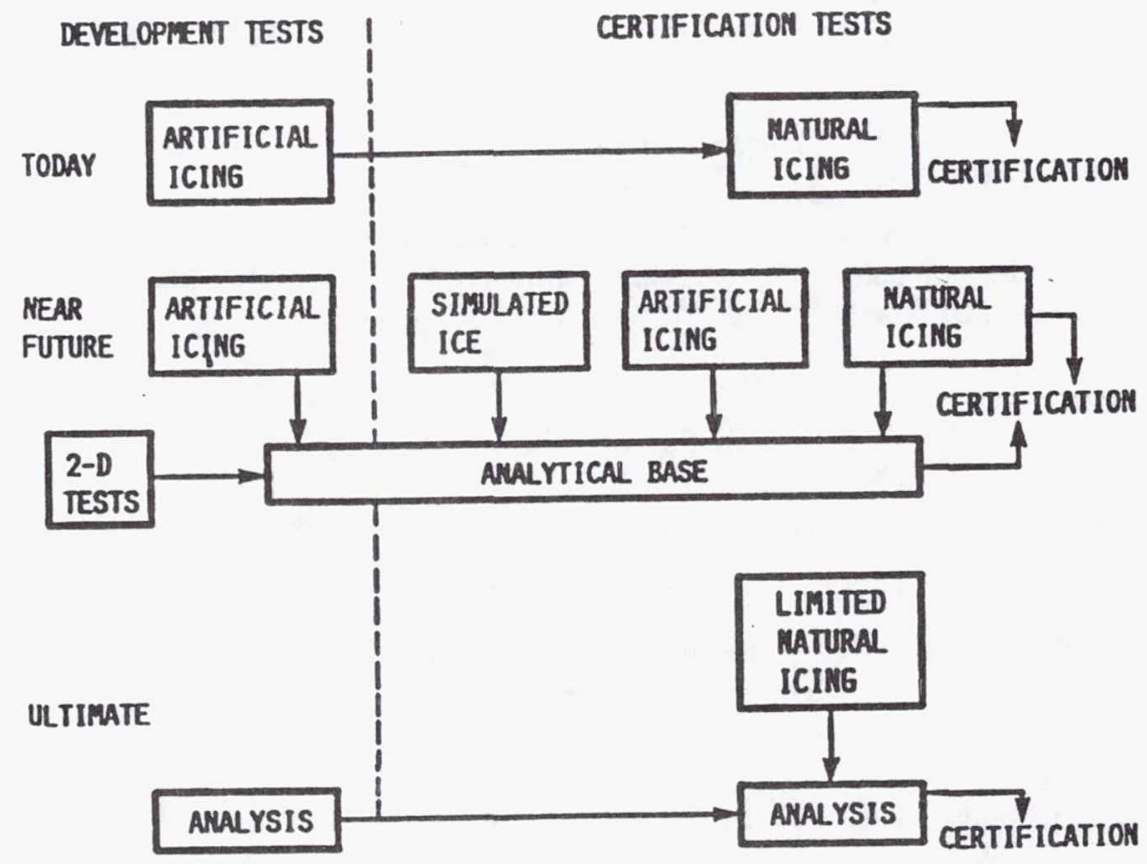

Figure 1. Certification flow diagram for rotorcraft icing. 


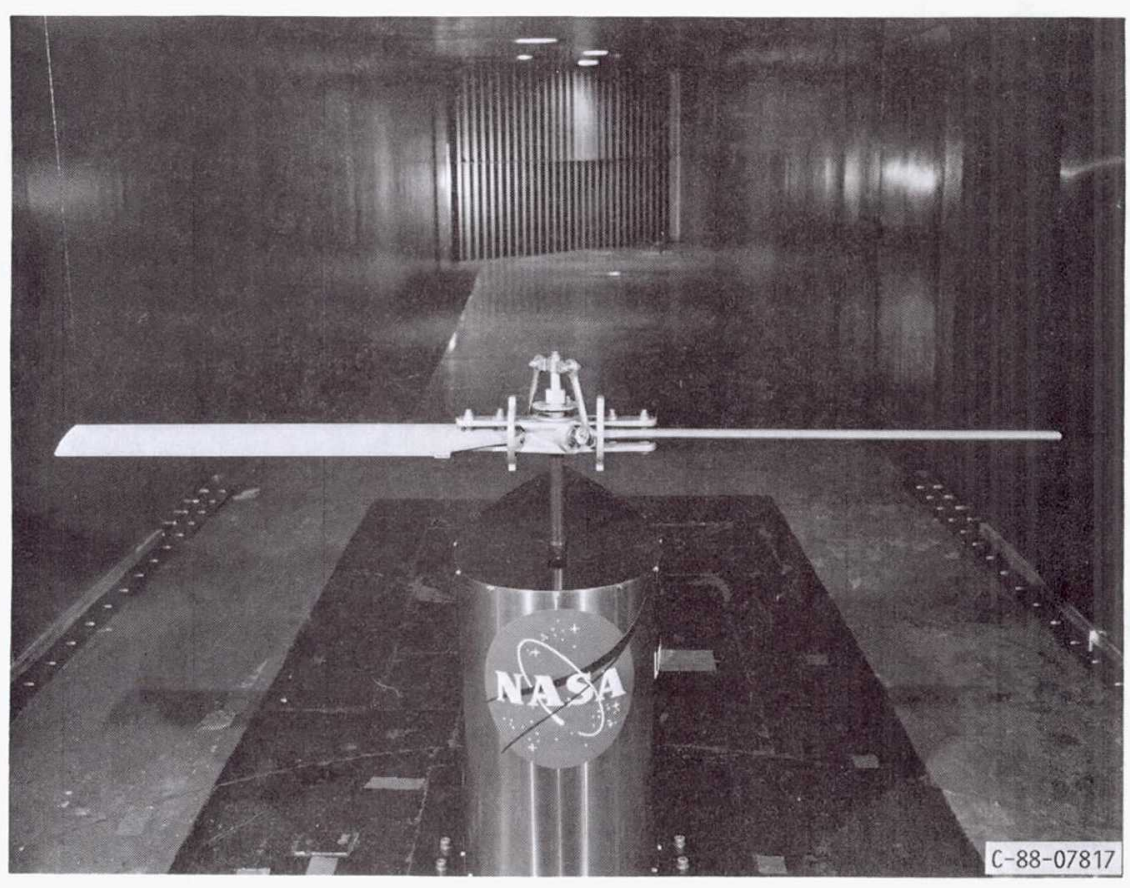

Figure 2. OH-58 Tail rotor assembly.

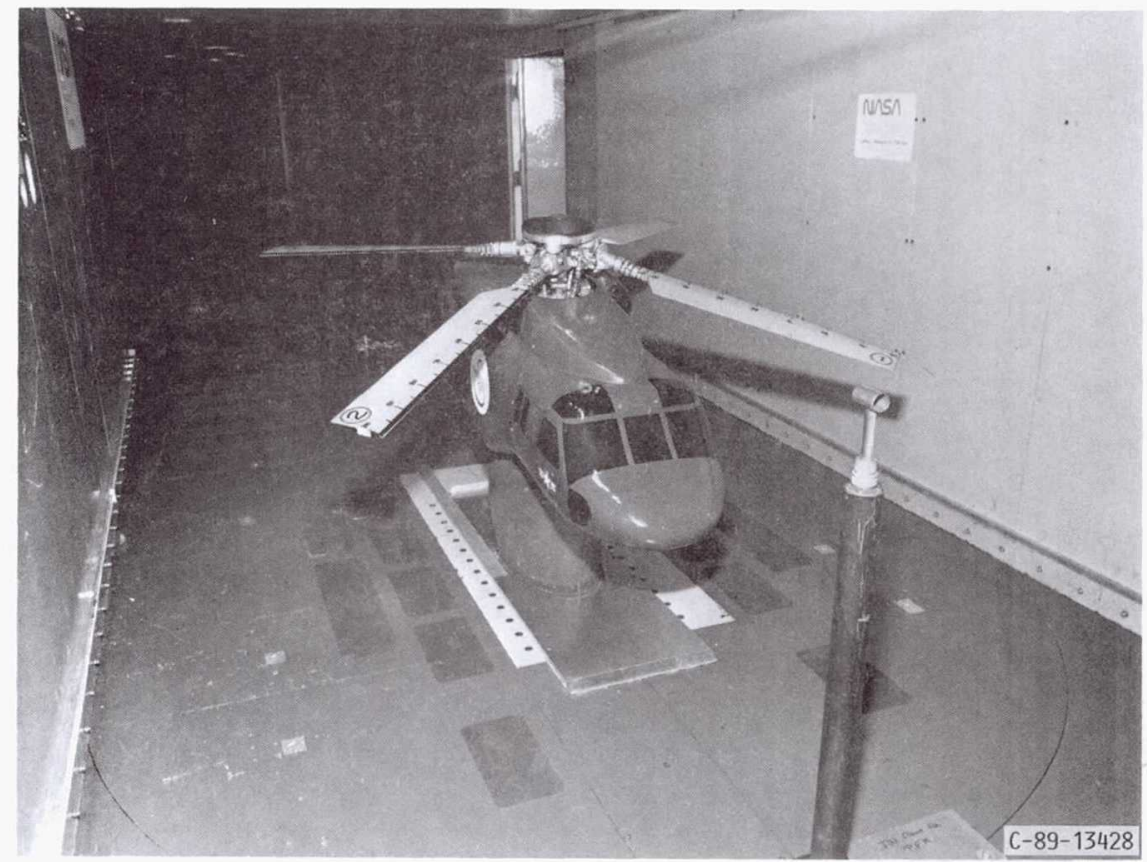

Figure 3. Model main rotor assembly in the IRT. 


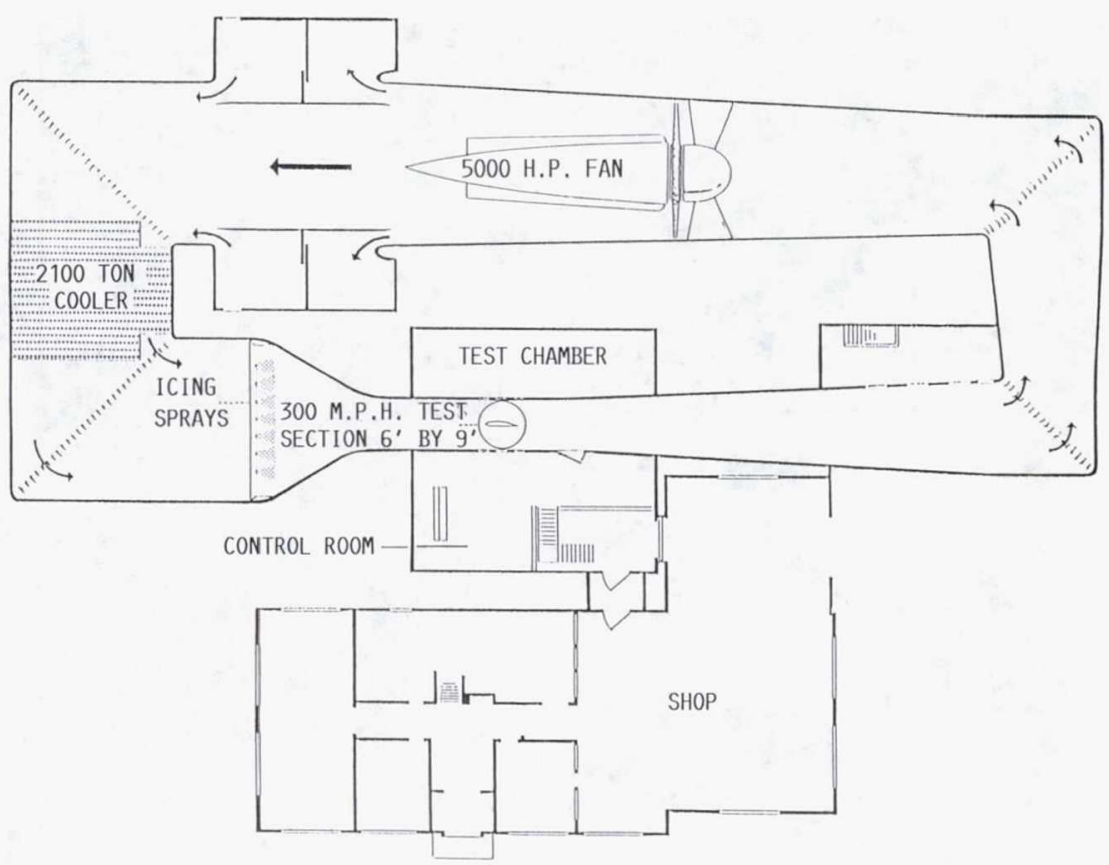

Figure 4. NASA Lewis Icing Research Tunnel.

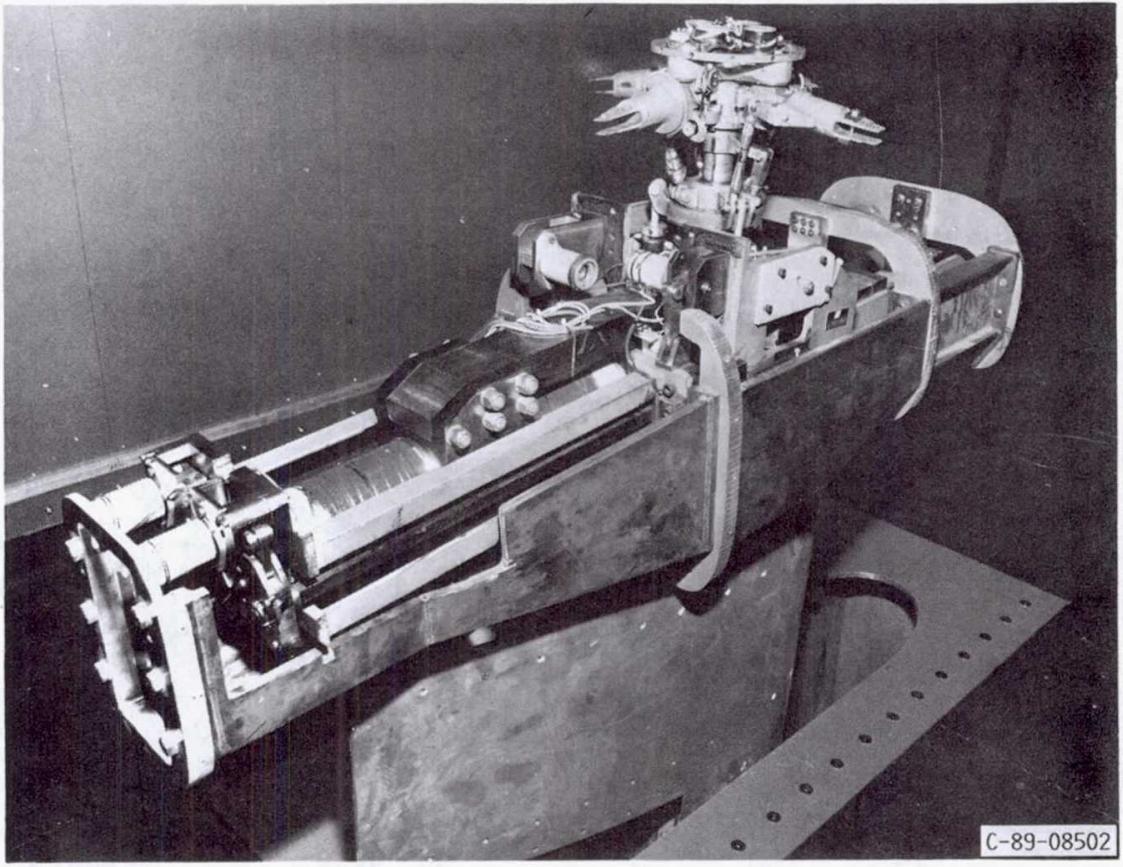

Figure 5. Sikorsky PFM rotor head and force balance assembly. 


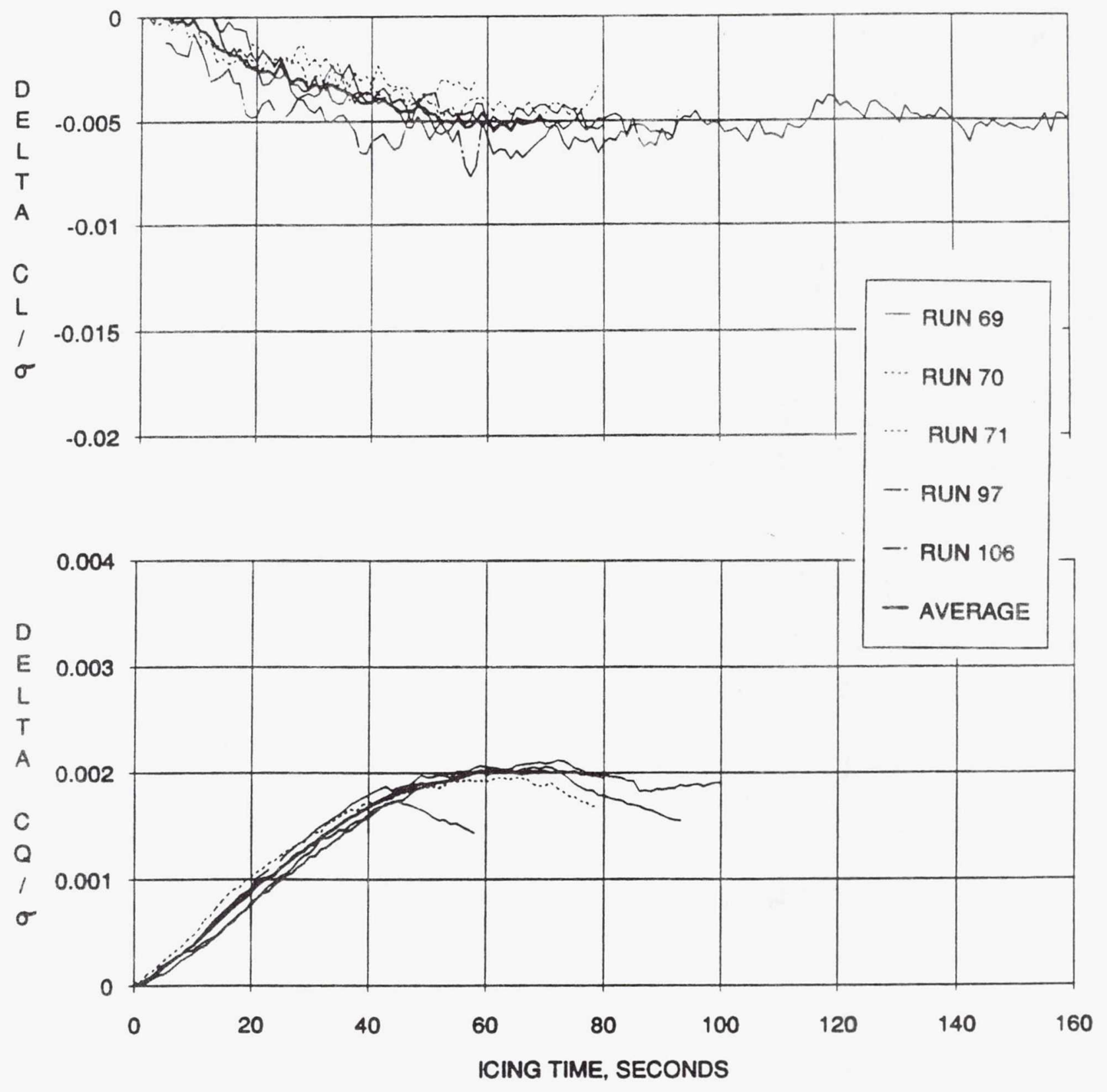

Figure 6. Repeatability $\left(\Omega R=205.7 \mathrm{~m} / \mathrm{s}, \mathrm{T}=-15^{\circ} \mathrm{C}\right)$. 


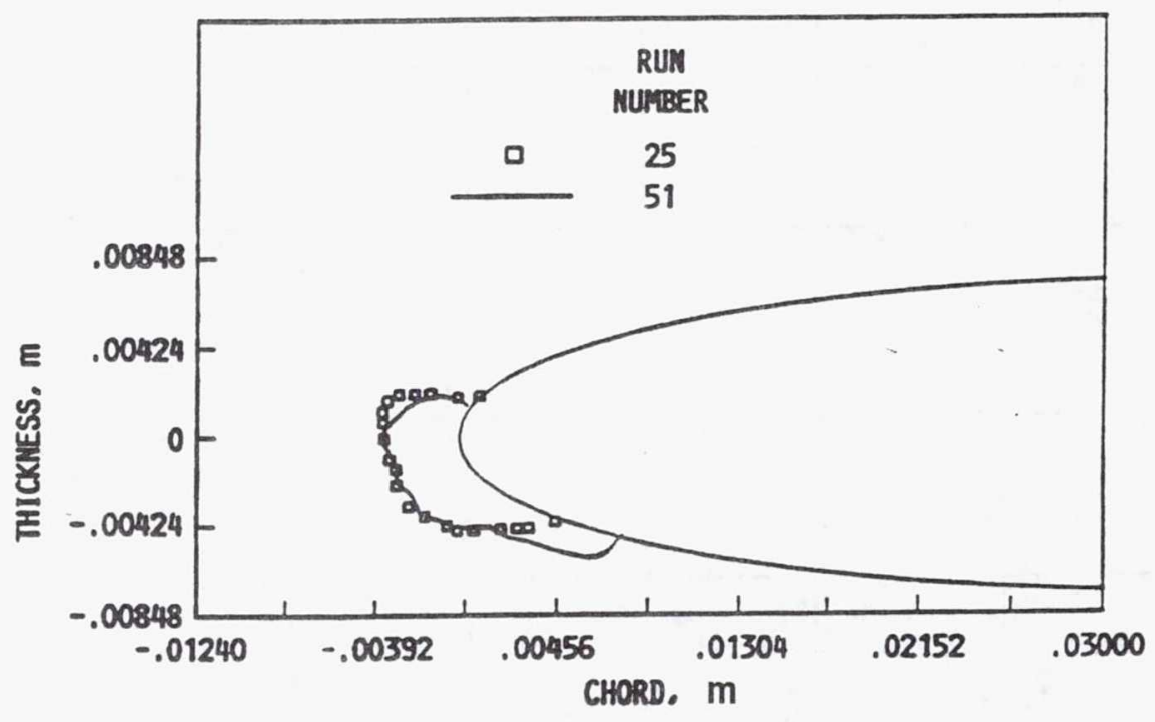

Figure 7. Two dimensional ice profiles ( $\mathrm{LWC}=0.5 \mathrm{~g} / \mathrm{m}^{3}, M V D=15 \mu \mathrm{m}$, $\left.\mu=0.20, \Omega R=183 \mathrm{~m} / \mathrm{s}, C_{L} / \sigma=0.064, T=-15^{\circ} \mathrm{C}\right)$. 

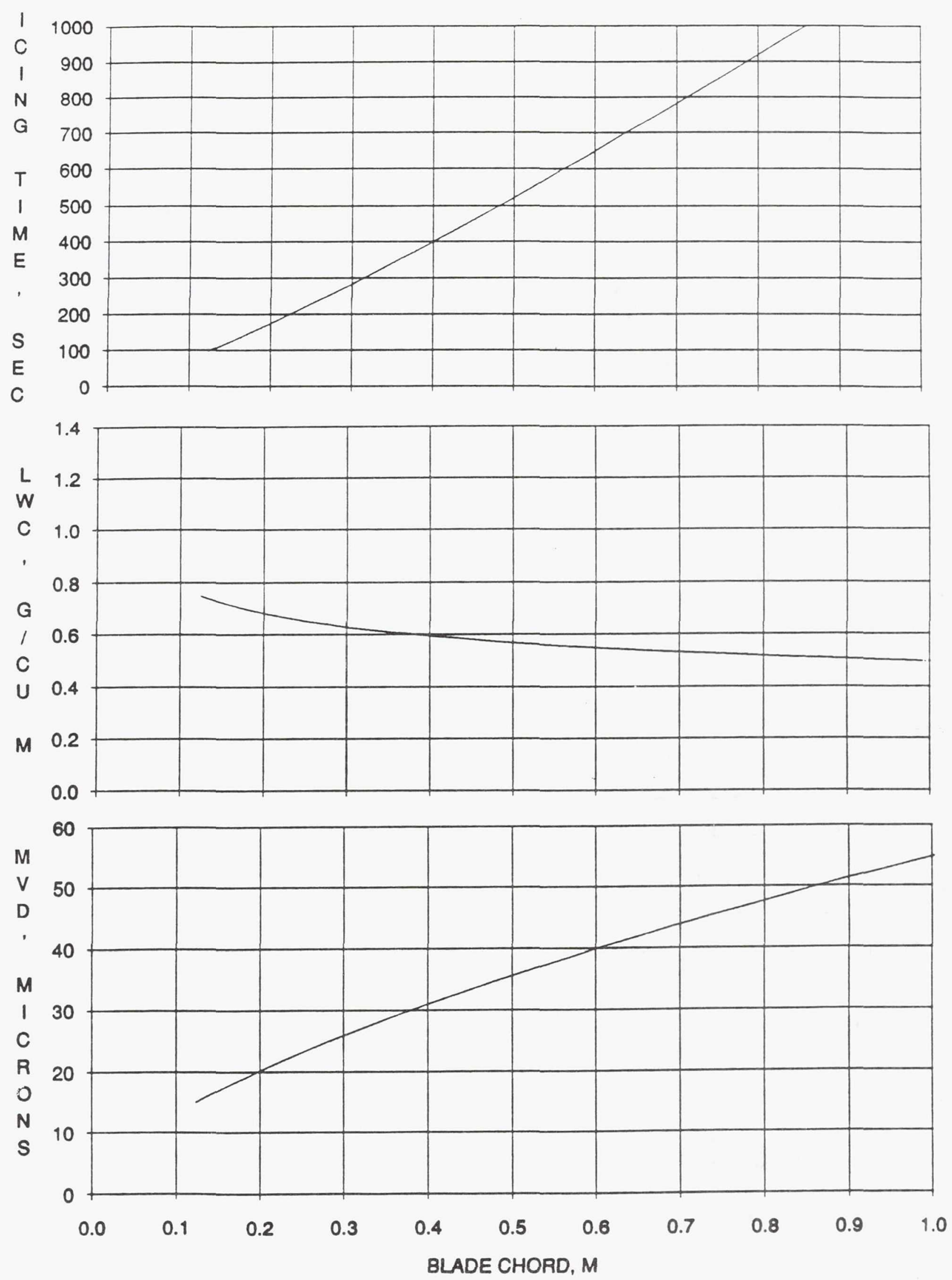

Figure 8. Icing similitude trends for icing time, LWC, and MVD. 


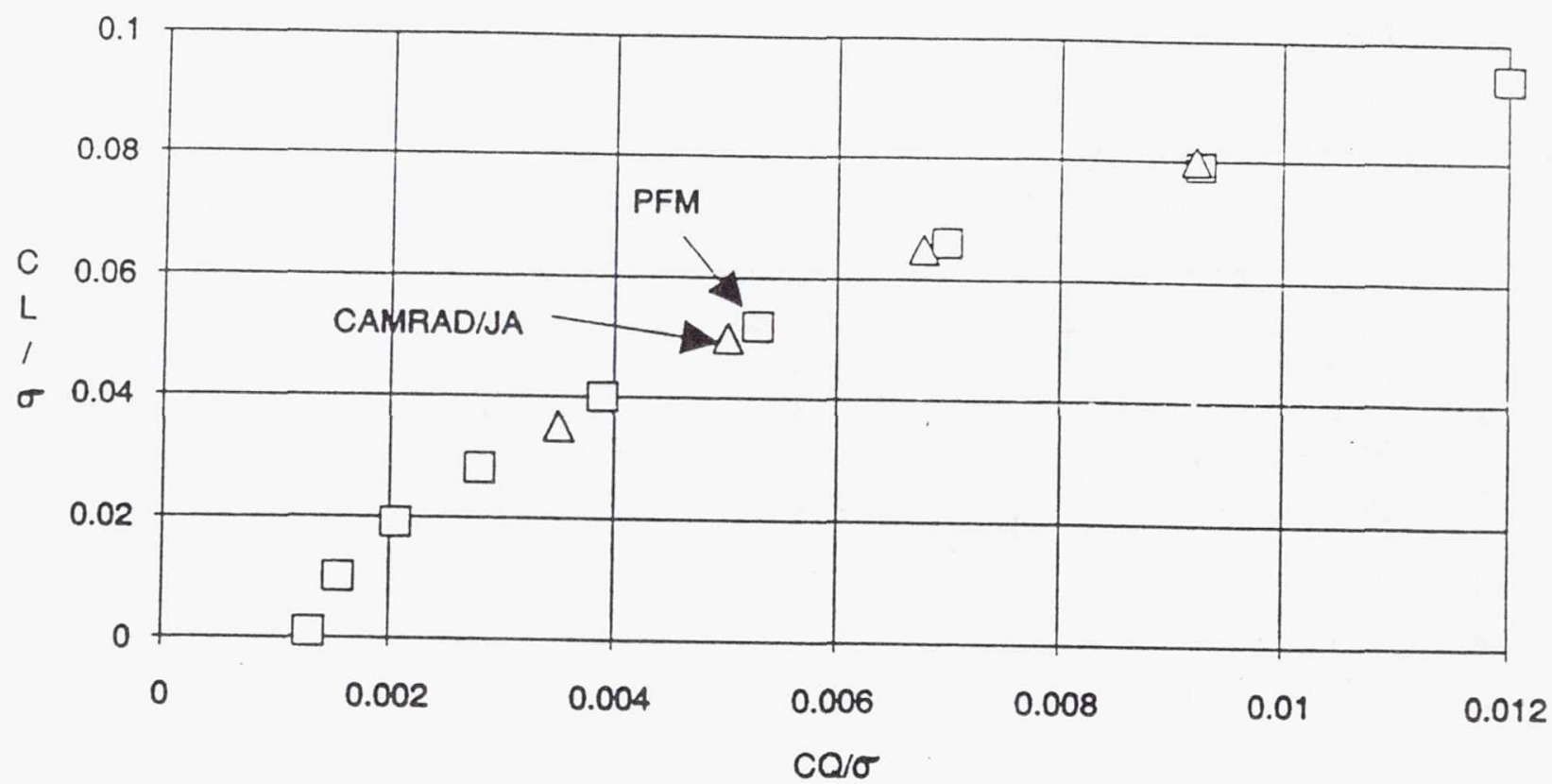

Figure 9. Rotor performance in hover.

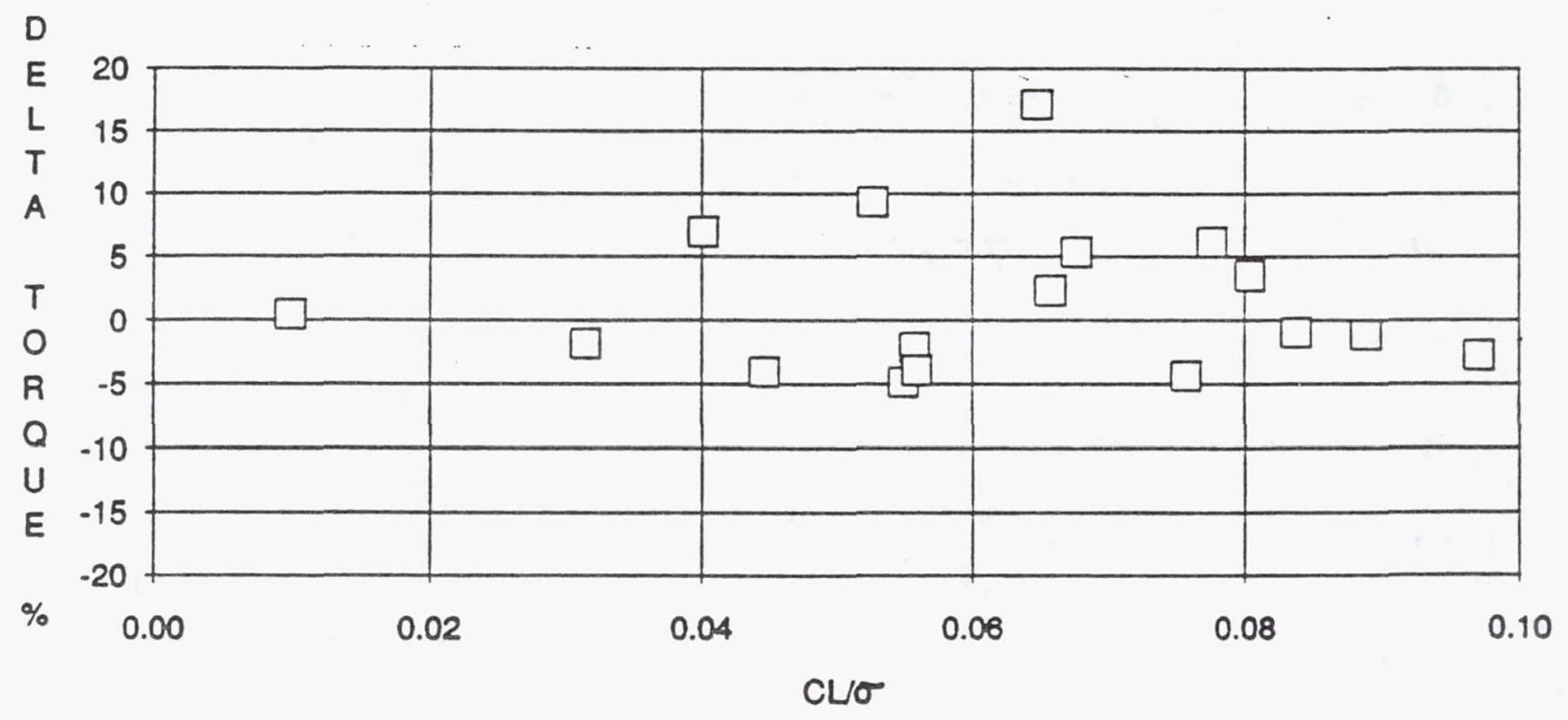

Figure 10. Difference between predicted and experimental torque in dry air. 


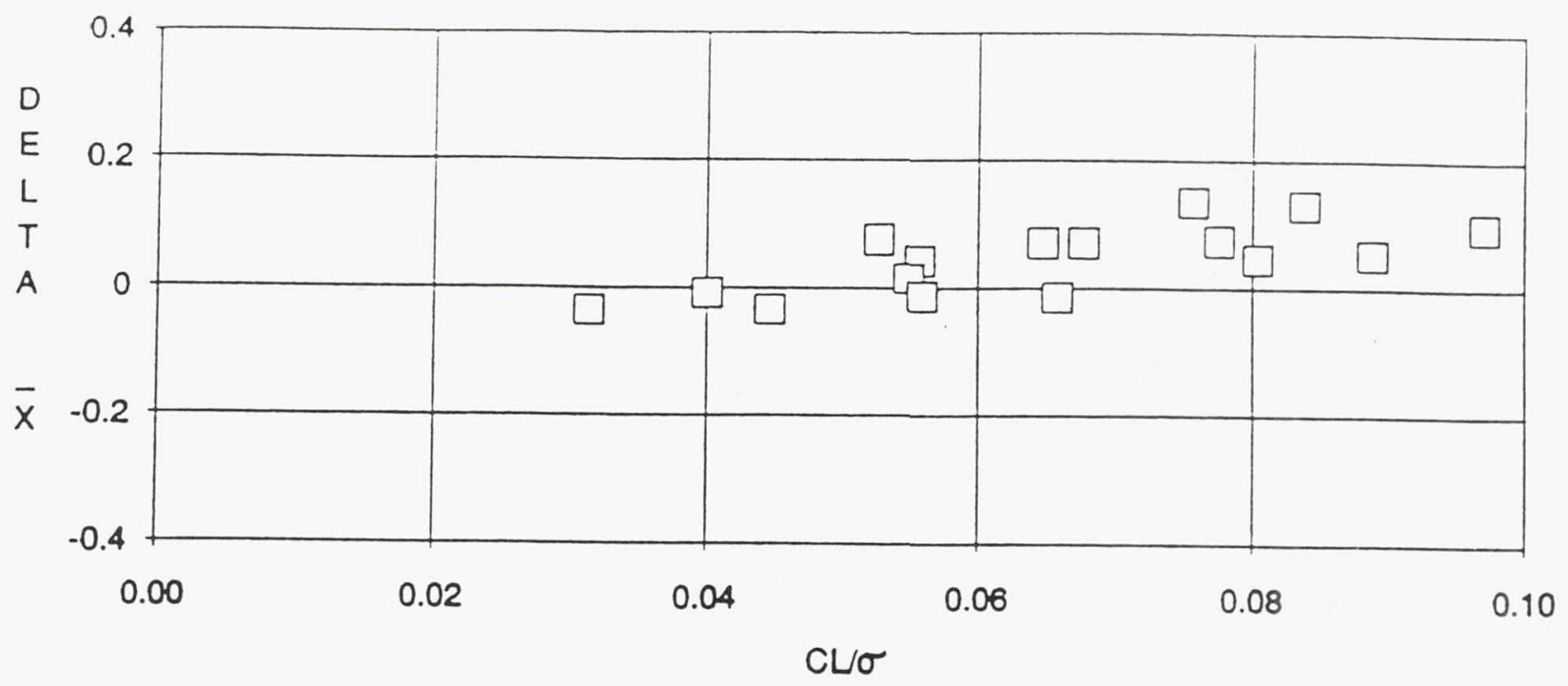

Figure 11. Difference between the predicted and experimental rotor propulsive force in dry air.

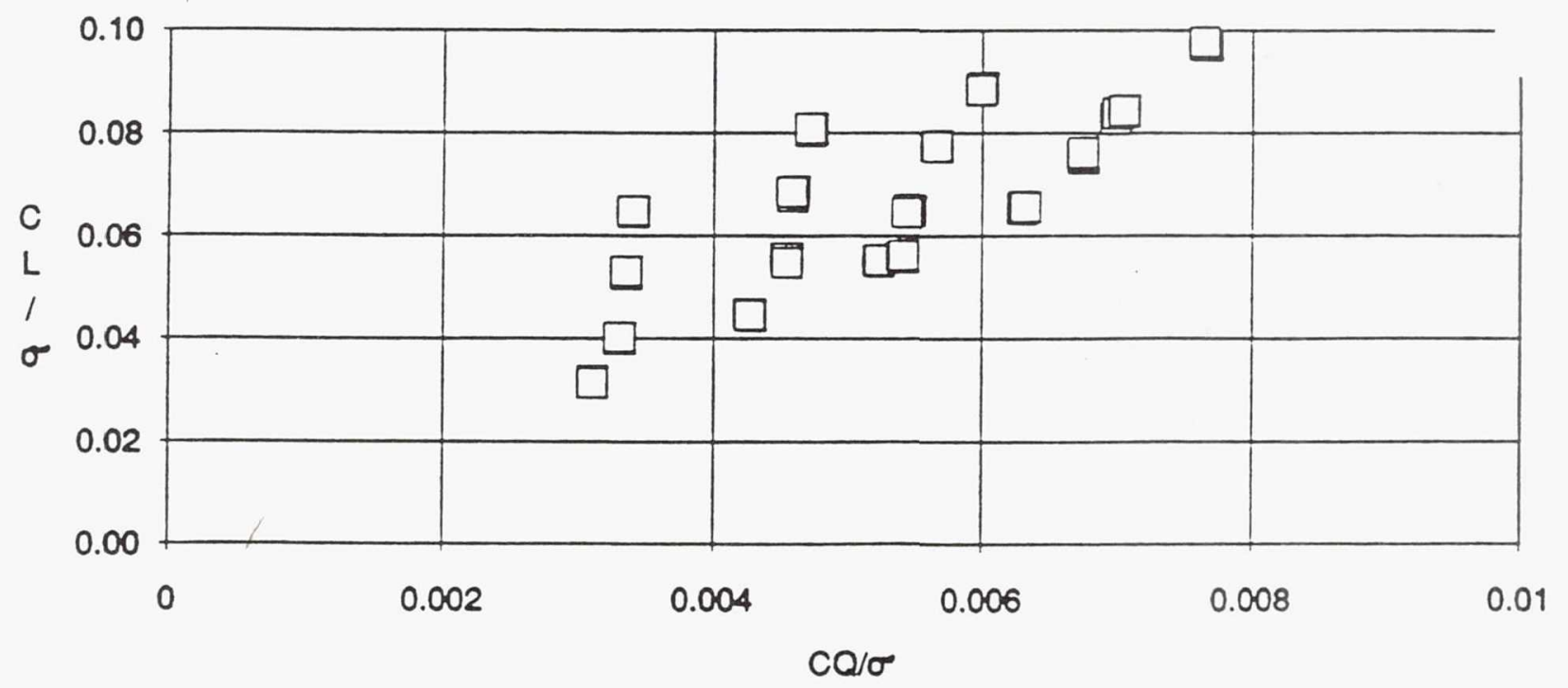

Figure 12. Rotor performance in dry air. 


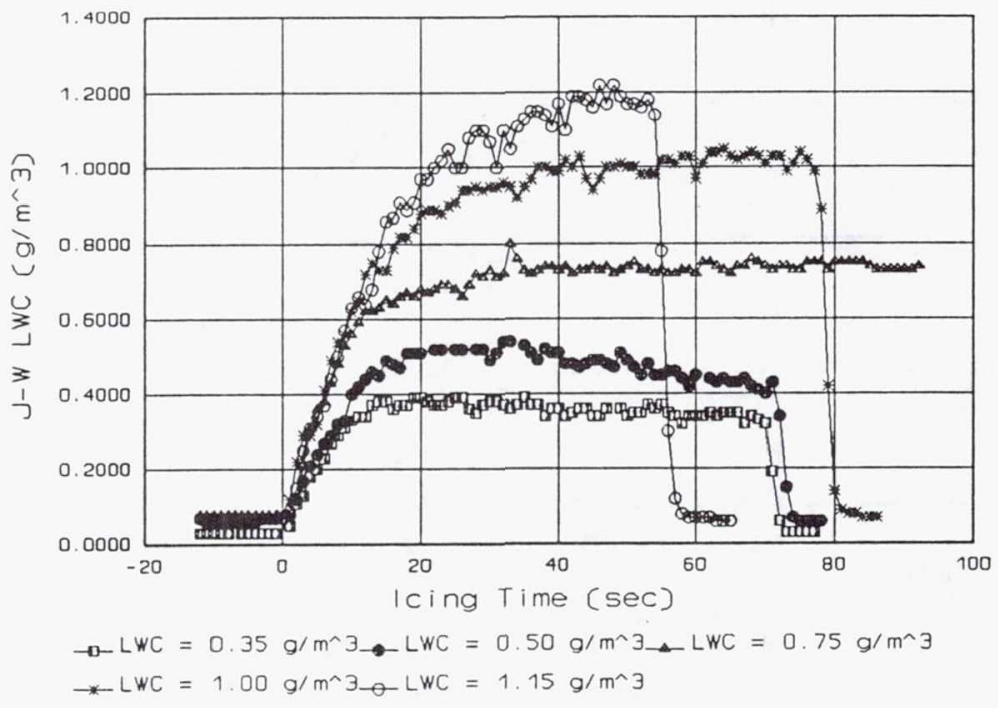

Figure 13. Various $L W C$ runs versus icing time (MVD $=15 \mu \mathrm{m}, \mu=$ $0.20, \Omega \mathrm{R}=206 \mathrm{~m} / \mathrm{s}, \mathrm{C}_{\mathrm{L}} / \sigma=0.064, \mathrm{~T}=-15^{\circ} \mathrm{C}$ ).

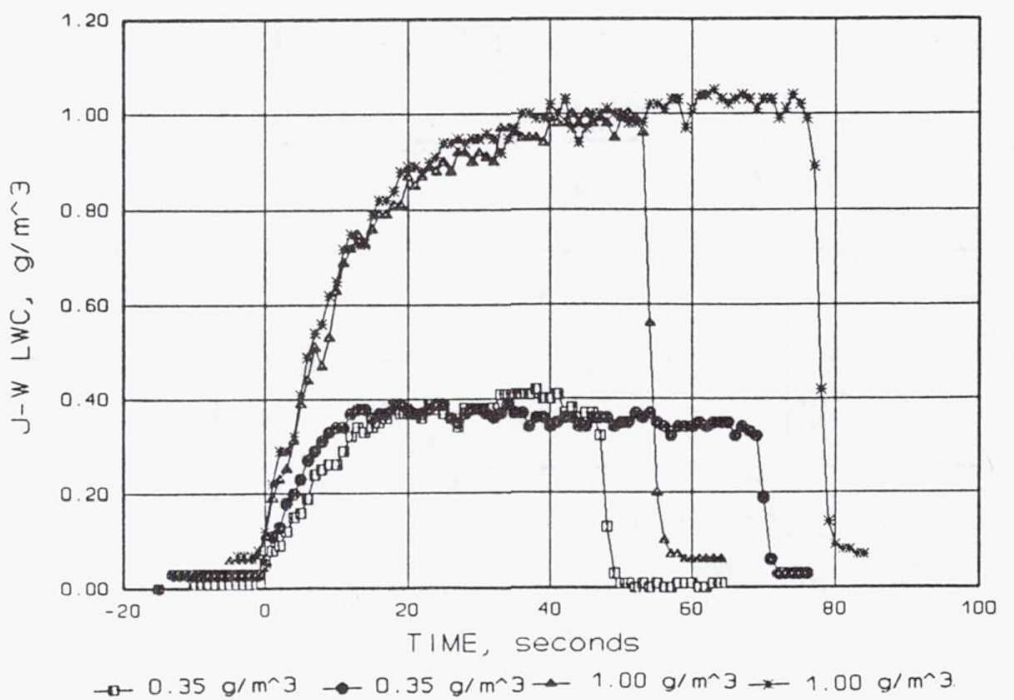

Figure 14. LWC repeatability versus icing time (MVD $=15 \mu \mathrm{m}, \mu=$ $0.20, \Omega \mathrm{R}=206 \mathrm{~m} / \mathrm{s}, \mathrm{C}_{\mathrm{L}} / \sigma=0.064, \mathrm{~T}=-15^{\circ} \mathrm{C}$ ). 


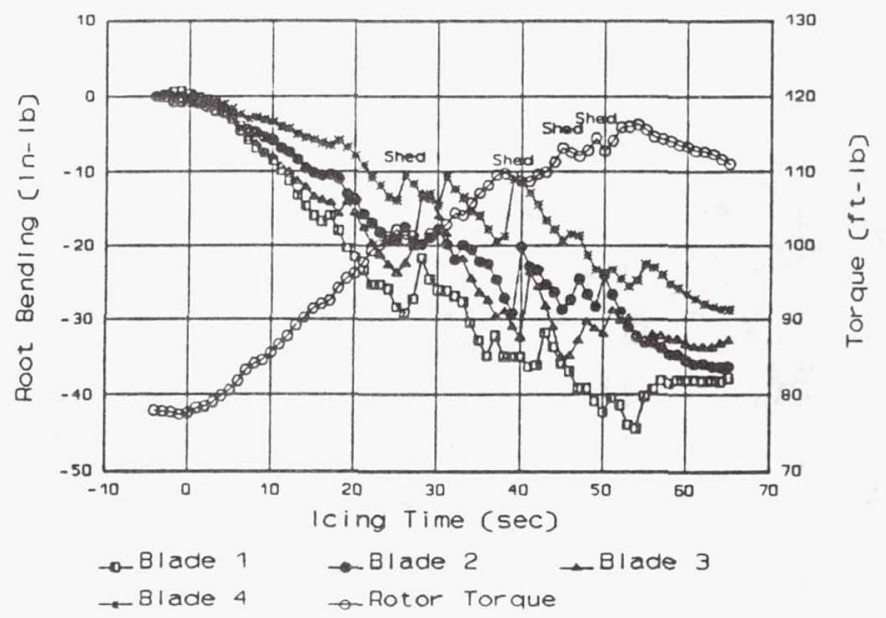

Figure 15. Blade root bending and torque rise versus icing time (LWC $=1.0 \mathrm{~g} / \mathrm{m}^{3}, \mathrm{MVD}=15 \mu \mathrm{m}, \mu=0.20, \Omega \mathrm{R}=206 \mathrm{~m} / \mathrm{s}, \mathrm{C}_{\mathrm{L}} / \sigma=0.064, \mathrm{~T}$ $=-15^{\circ} \mathrm{C}$ ).

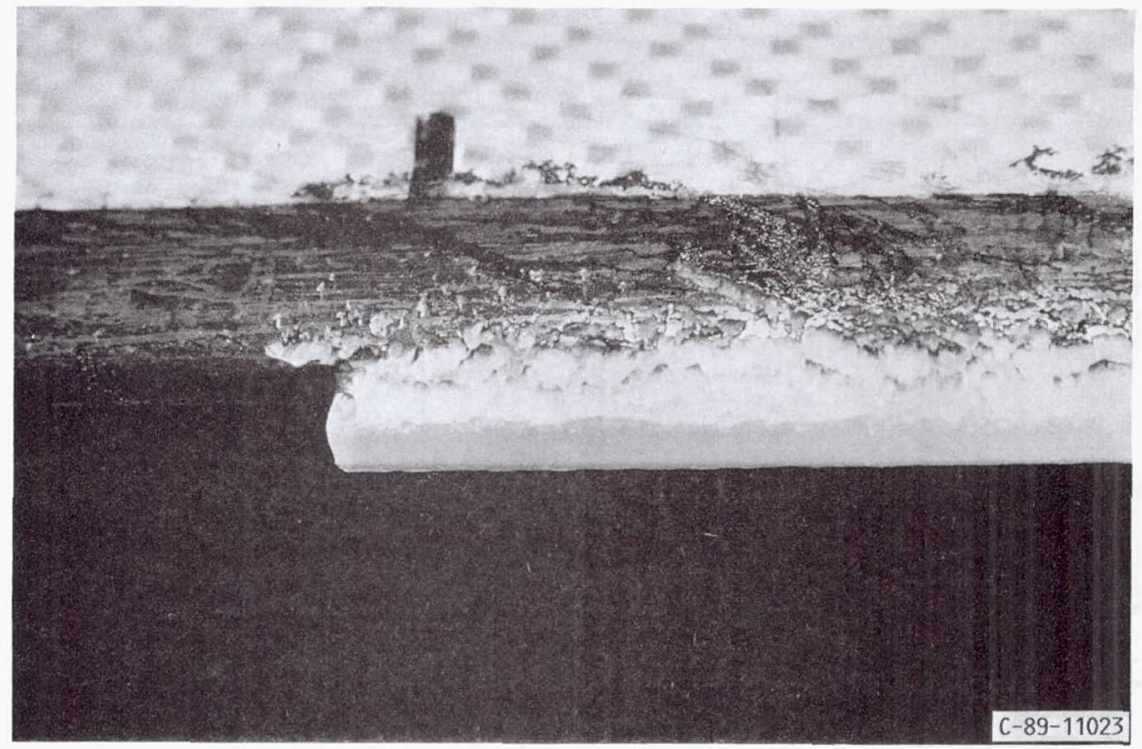

Figure 16. Close-up detail of shed ice. 

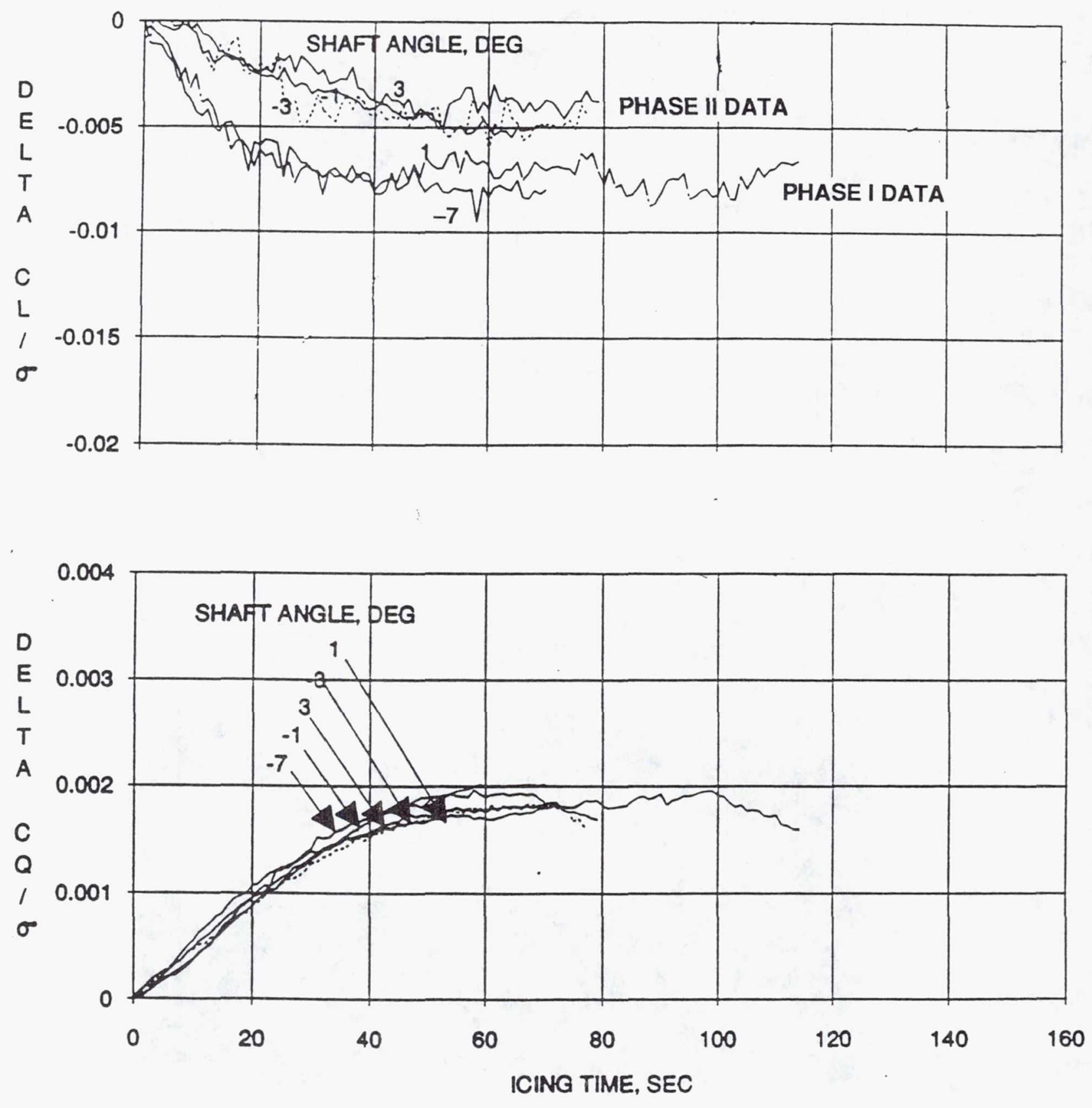

Figure 17. Effect of shaft angle $\left(C_{L} / \sigma=0.064\right)$. 

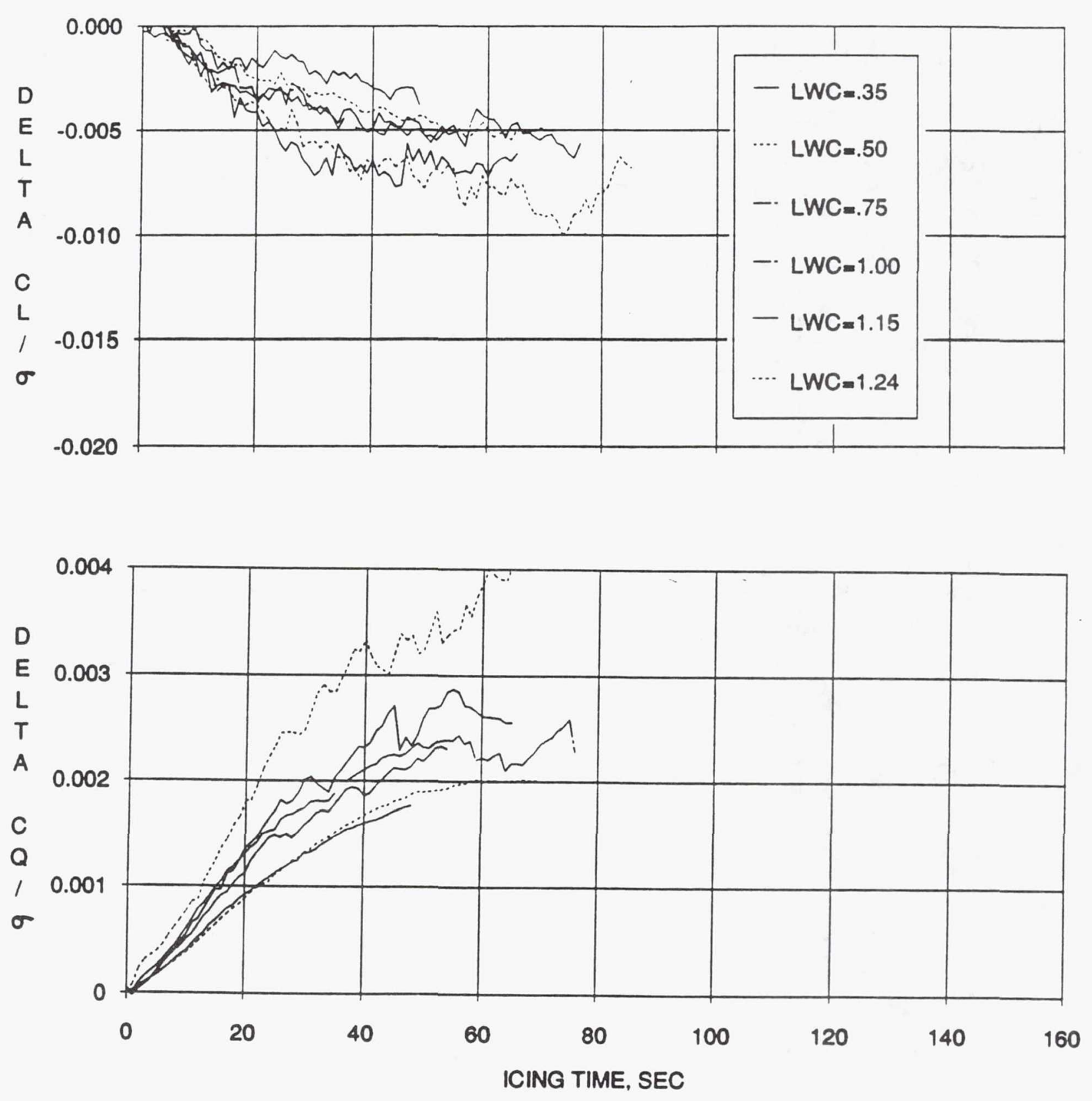

Figure 18. Effect of liquid water content $\left(T=-15^{\circ} \mathrm{C}\right)$. 

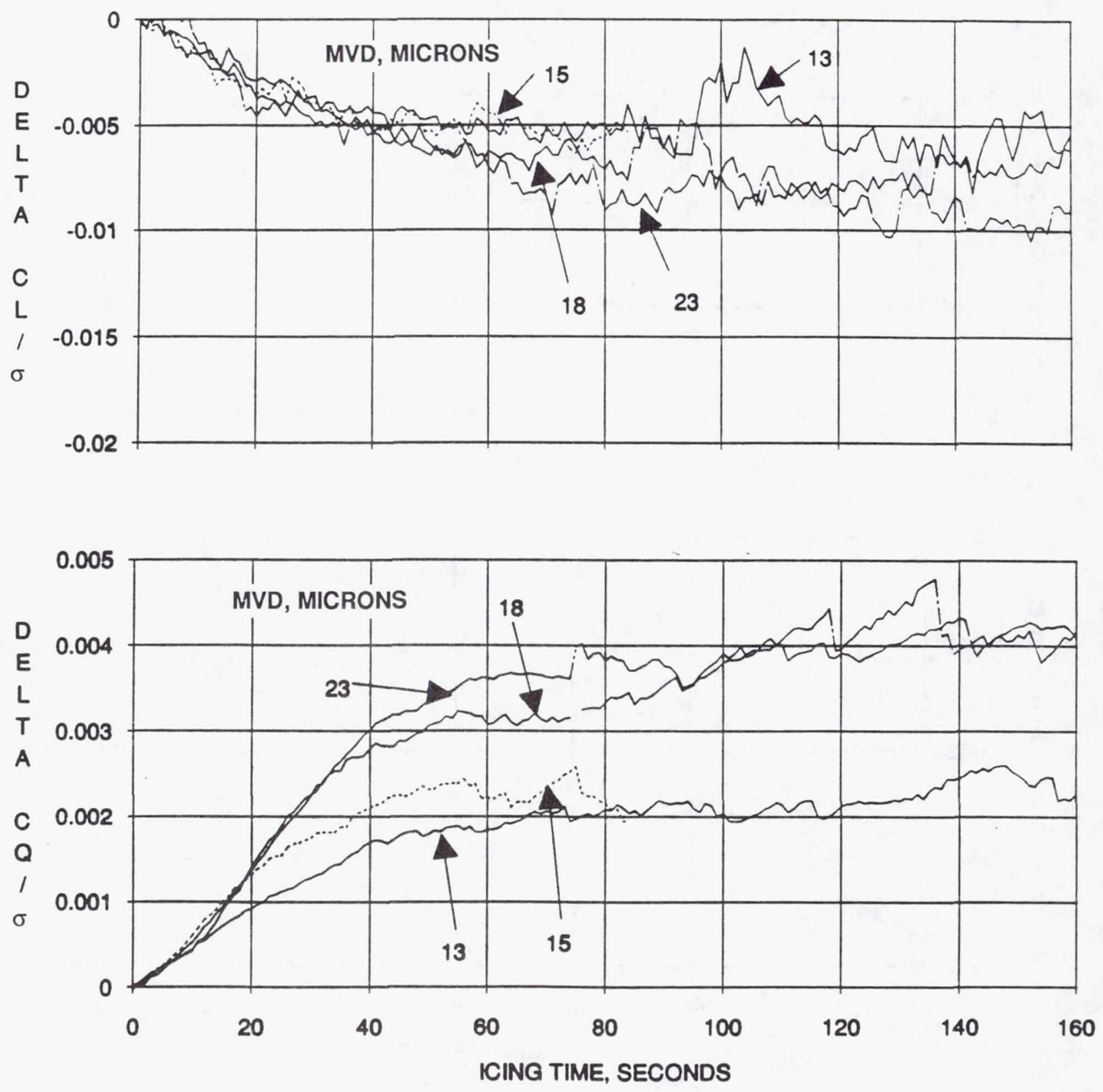

Figure 19. Effect of droplet diameter $\left(\mathrm{LWC}=0.75 \mathrm{~g} / \mathrm{m}^{3}\right)$. 

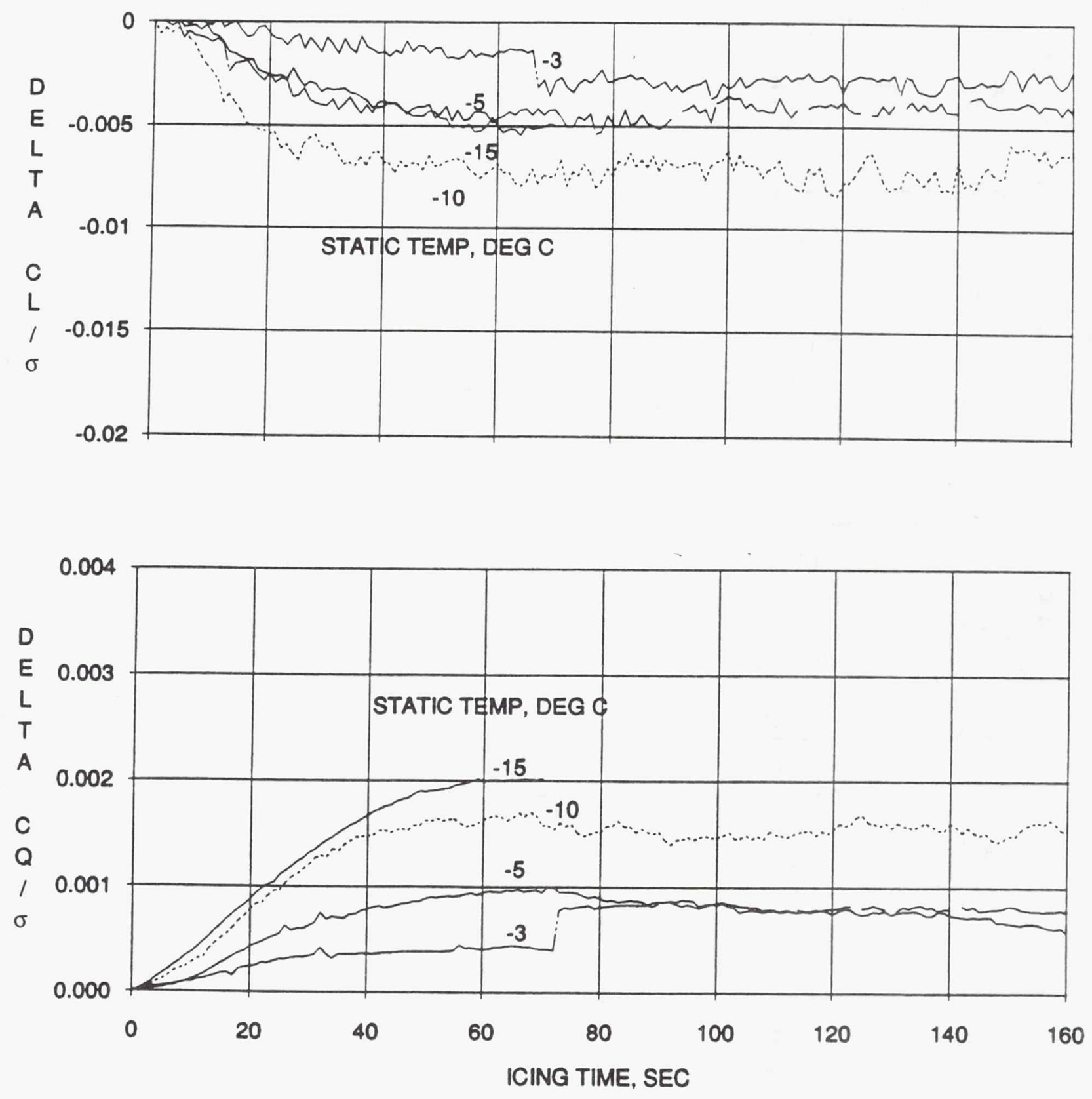

Figure 20. Effect of temperature $(\Omega R=205.7 \mathrm{~m} / \mathrm{s}$, warmer temp. $)$. 

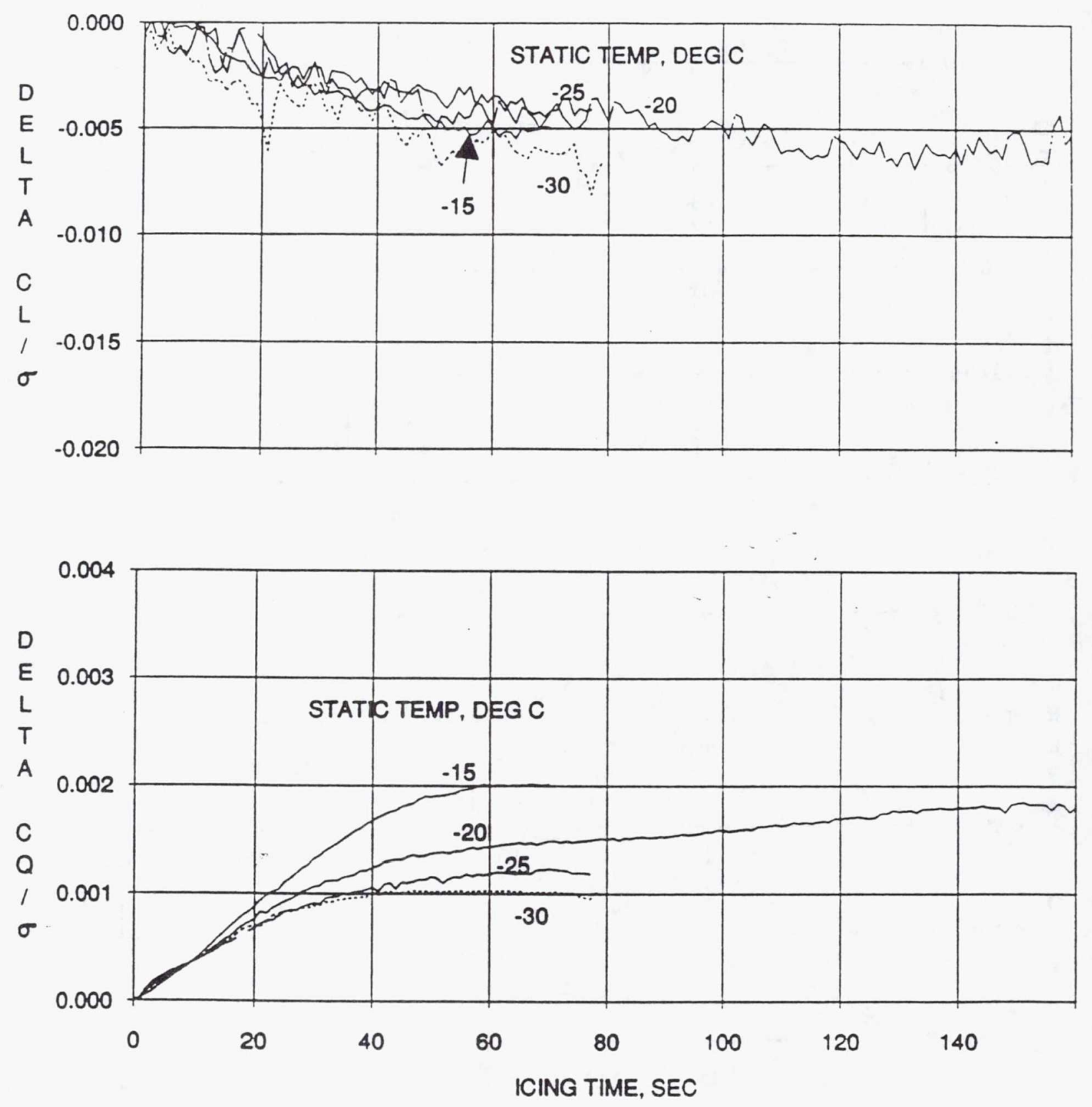

Figure 21. Effect of temperature $(\Omega R=205.7 \mathrm{~m} / \mathrm{s}$, colder temp. $)$. 

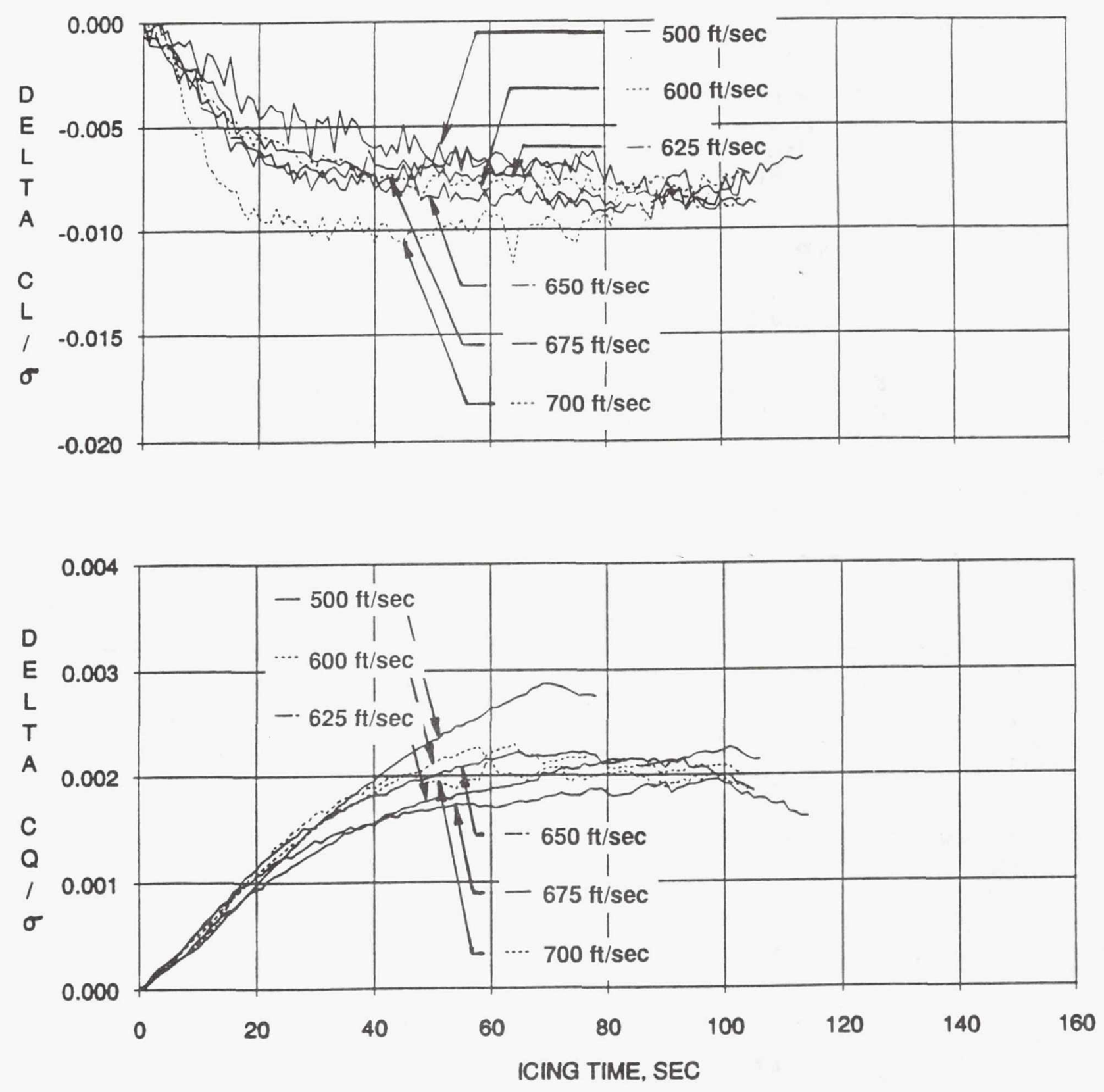

Figure 22. Effect of tip speed. 


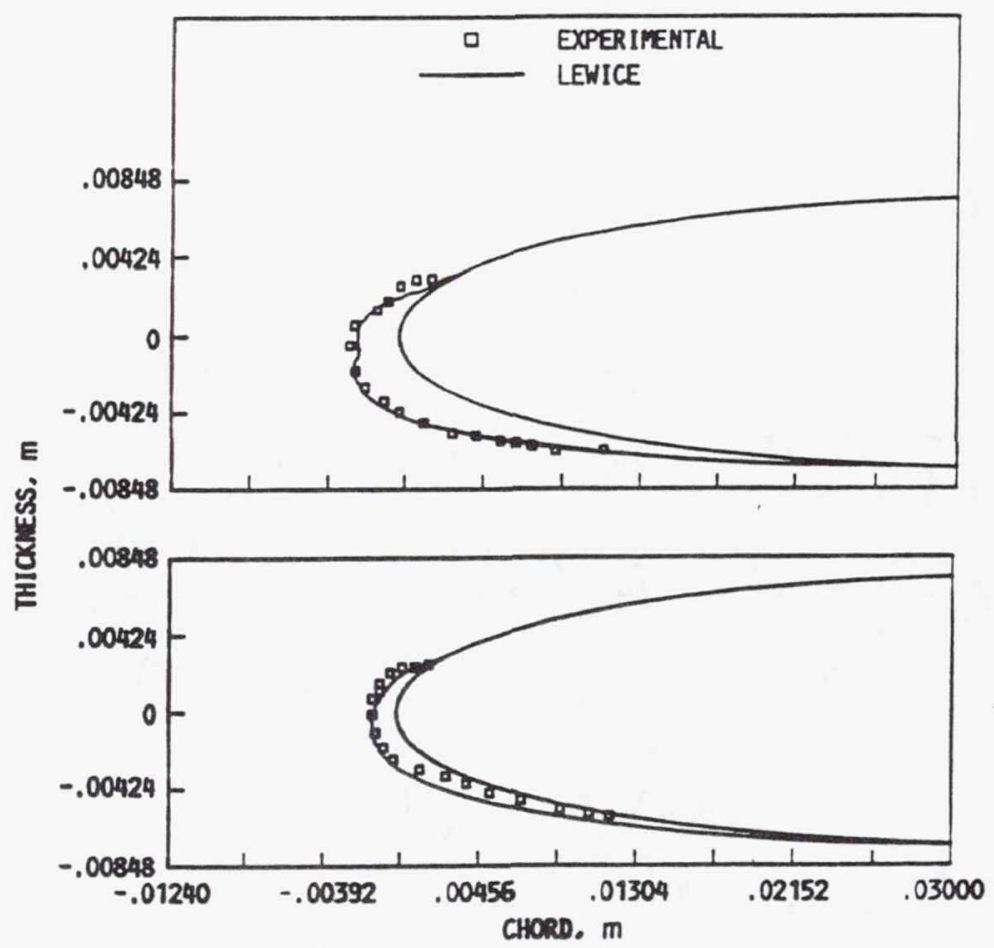

Figure 23. Comparison between experimental and theoretical ice shapes $\left(\mathrm{LWC}=1.0 \mathrm{~g} / \mathrm{m}^{3}, \mathrm{MVD}=15 \mu \mathrm{m}, \mu=0.2, \Omega \mathrm{R}=206 \mathrm{~m} / \mathrm{s}, \mathrm{C}_{\mathrm{L}} / \sigma\right.$ $\left.=0.064, \mathrm{~T}=-15^{\circ} \mathrm{C}\right)$.

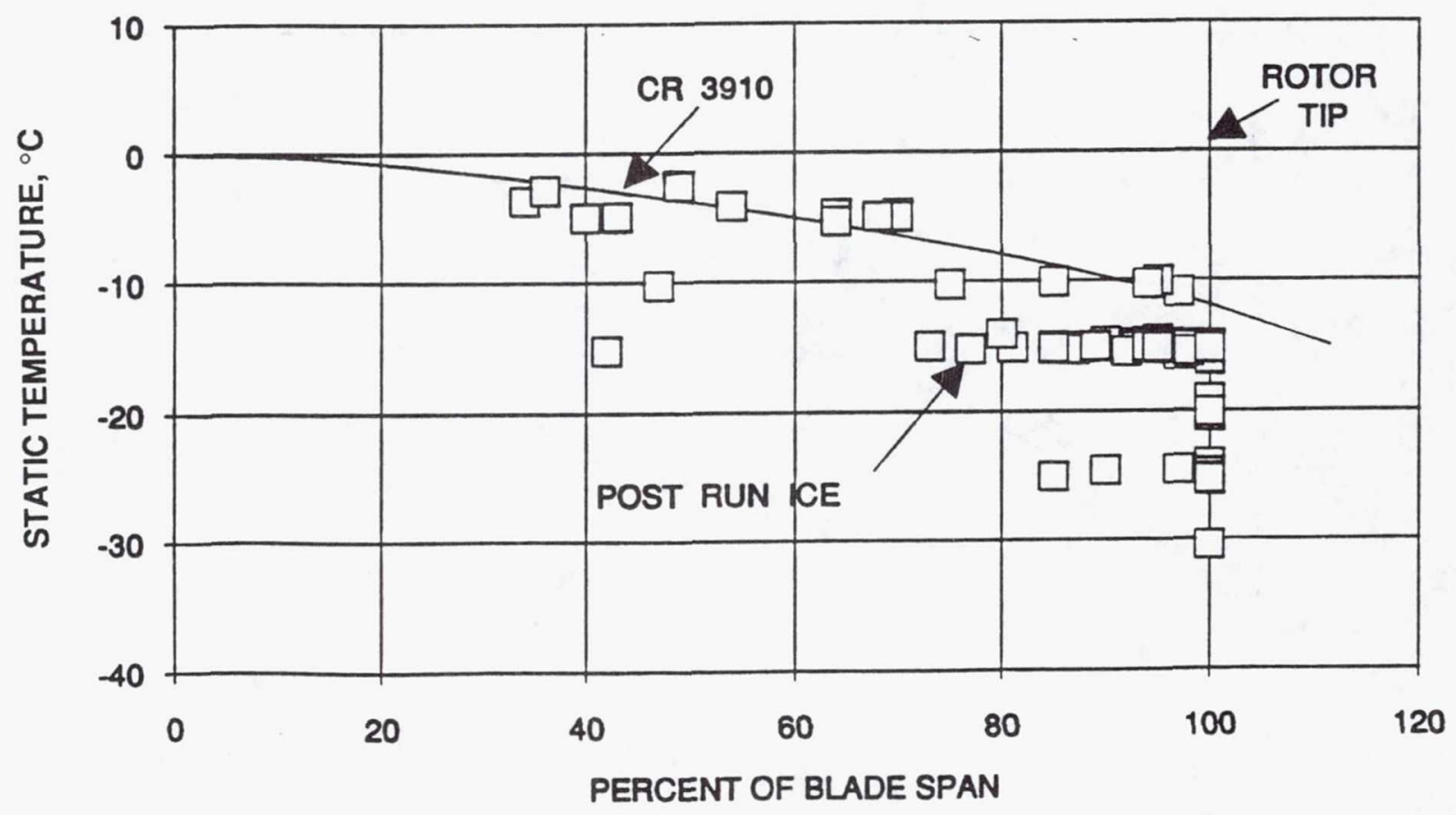

Figure 24. Observed and predicted model rotor ice extent. 


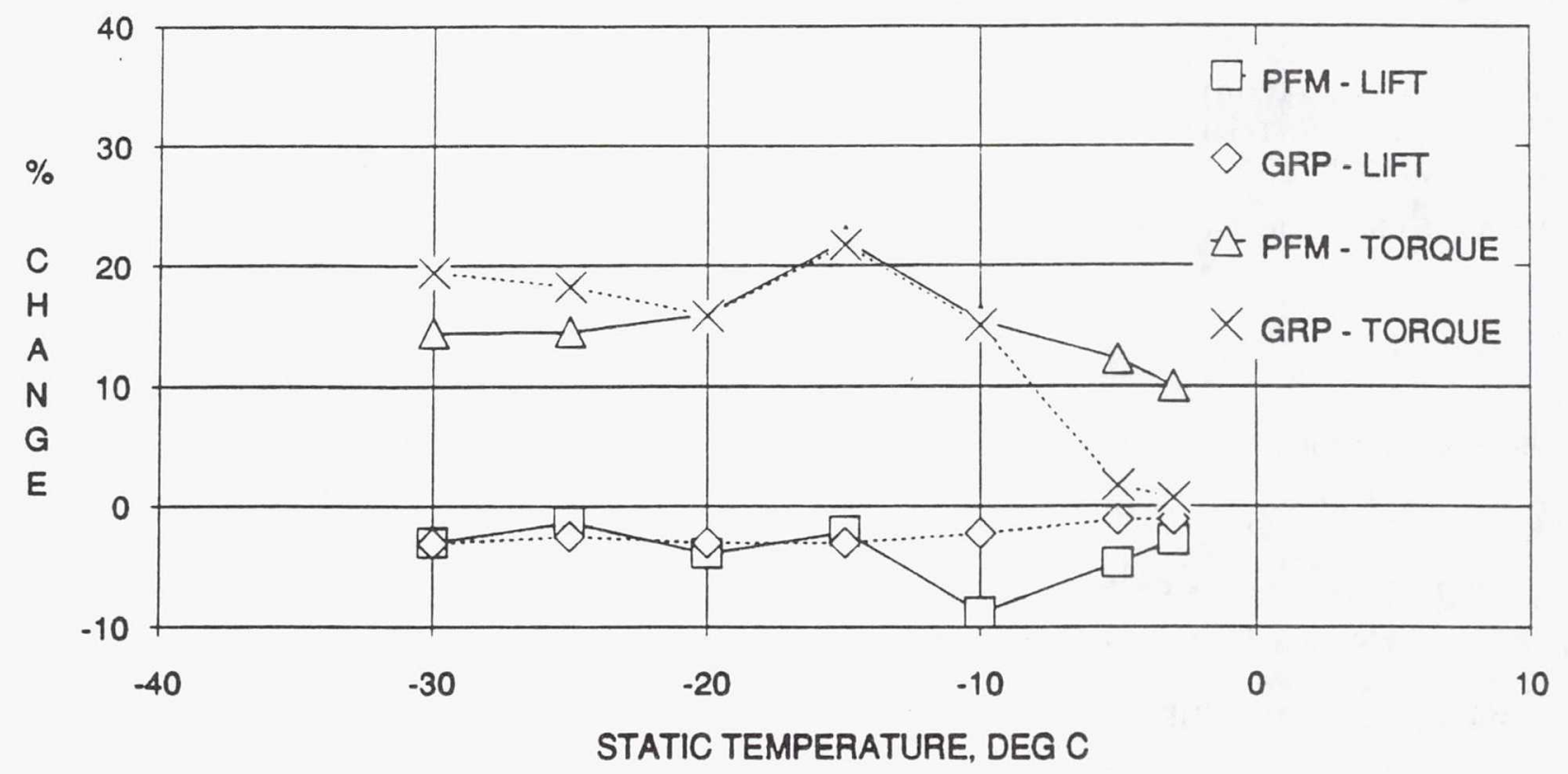

Figure 25. Lift and torque change summary $(\tau=20 \mathrm{sec}$., $\mathrm{LWC}=0.5$ $\left.\mathrm{g} / \mathrm{m}^{3}\right)$.

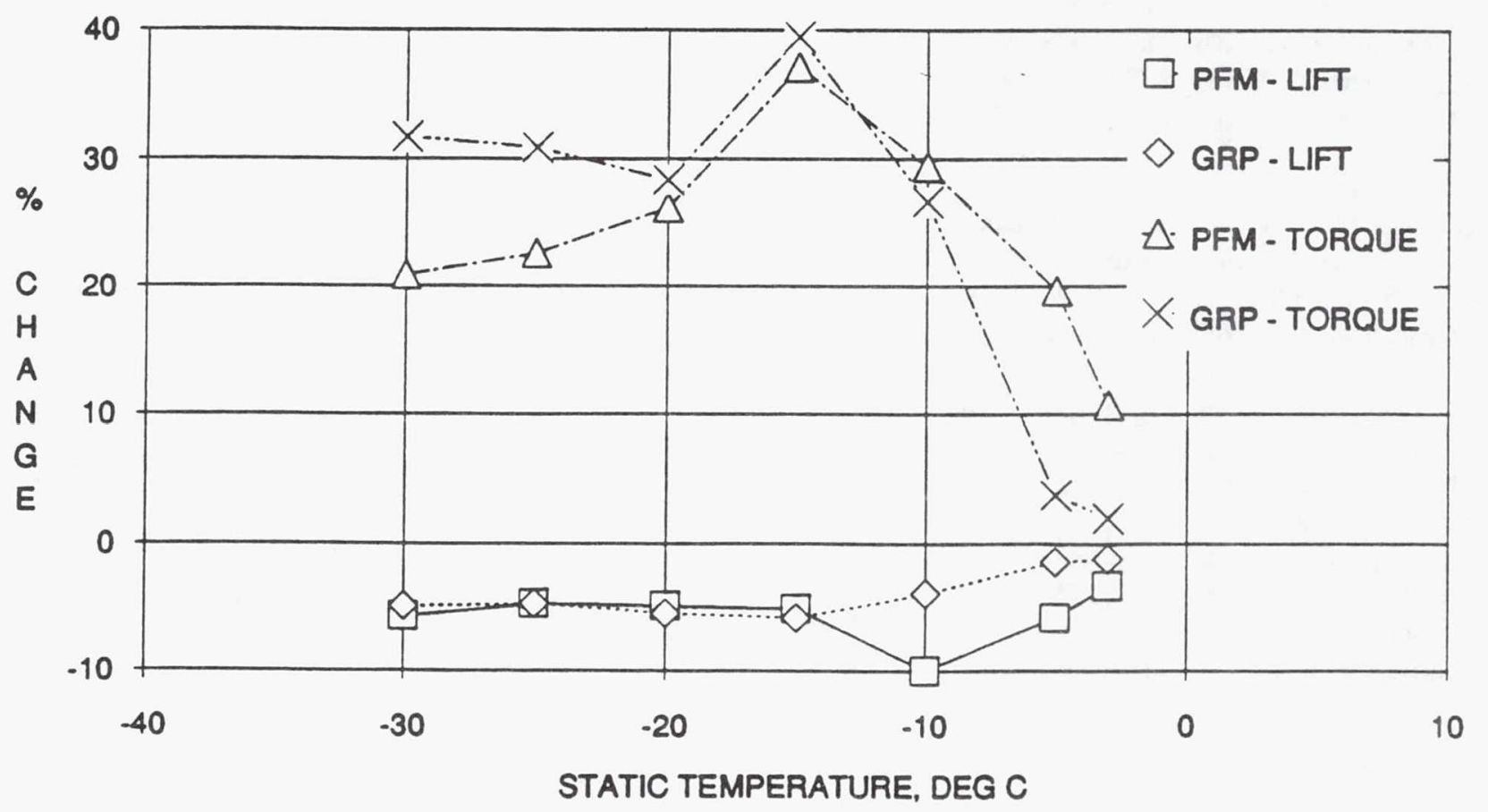

Figure 26. Lift and torque change summary $(\tau=40 \mathrm{sec}$., LWC $=0.5$ $\left.\mathrm{g} / \mathrm{m}^{3}\right)$. 


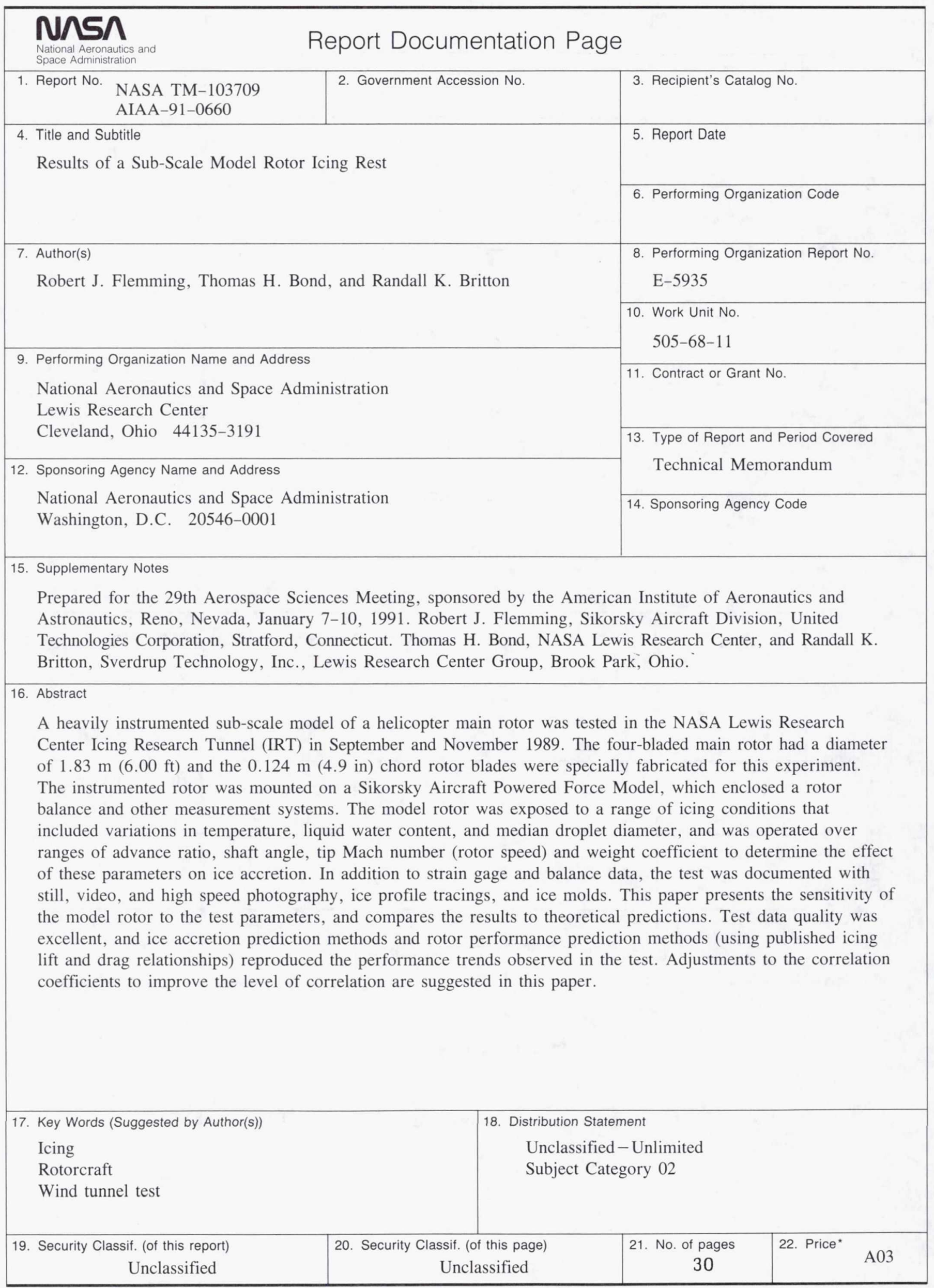

